INTERNATIONAL PHASE OF OCEAN DRILLING (IPOD)

DEEP SEA DRILLING PROJECT

Vadur

DEVELOPMENT ENGINEERING

TECHNICAL REPORT NO. 23

\title{
OPERATIONS PLAN
}

REVISED FEB. 241984

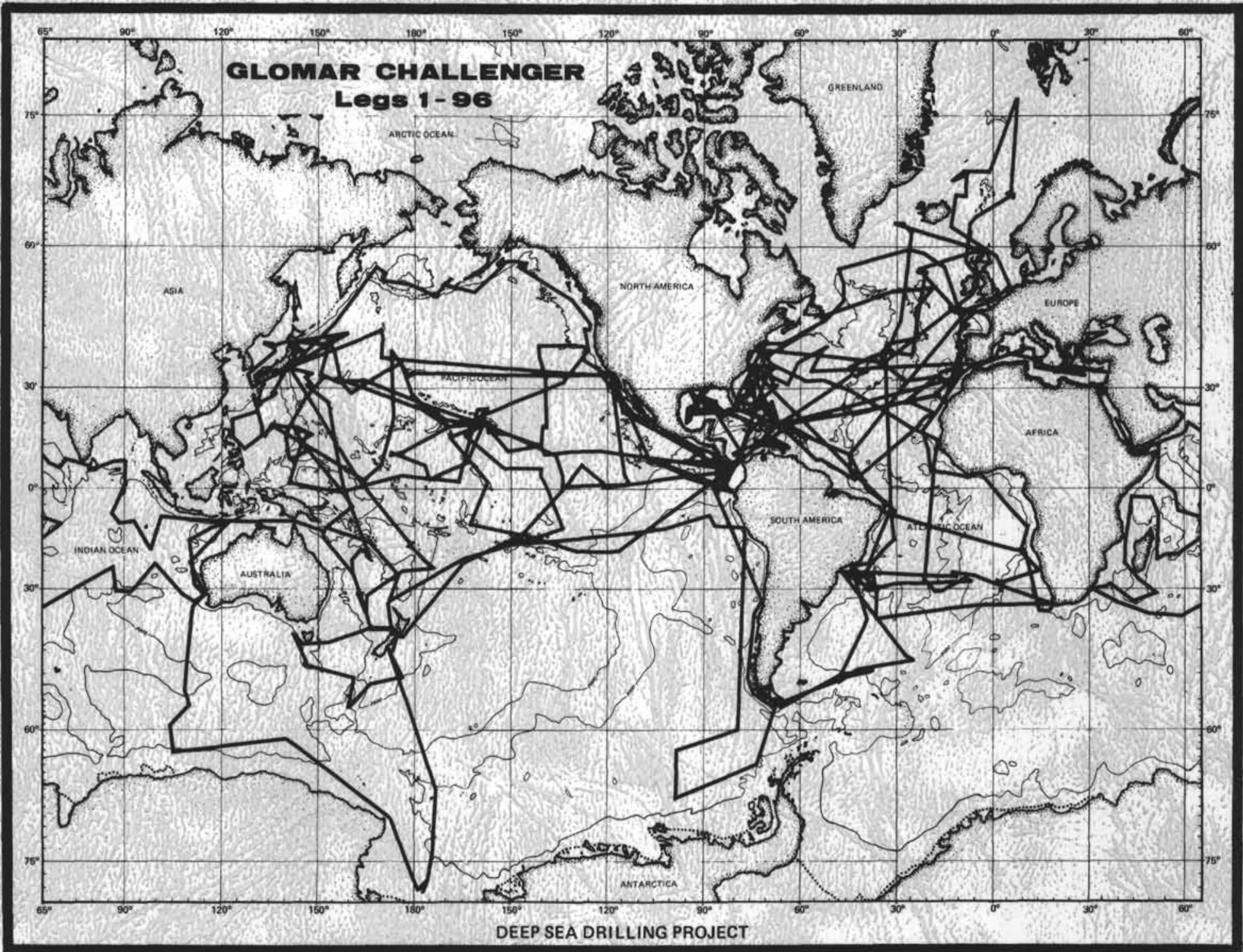

SCRIPPS INSTITUTION OF OCEANOGRAPHY UNIVERSITY OF CALIFORNIA AT SAN DIEGO CONTRACT NSF C-482

PRIME CONTRACTOR: THE REGENTS, UNIVERSITY OF CALIFORNIA 
DISCLAIMER

This report was prepared by the Deep Sea Drilling Project, University of California, San Diego, as an account of work sponsored by the United States Government's National Science Foundation. Neither the University nor any of their employees, nor any of their contractors, subcontractors, or their employees, makes any warranty, express or implied, or assumes any legal liability or responsibility for the accuracy, completeness or usefulness of any information, apparatus, product or process disclosed, or represents that its use would not infringe privately owned rights. 
TECHNICAL REPORT NO. 23

Operations Plan

\author{
Prepared for the \\ National Science Foundation \\ National Ocean Sediment Coring Program \\ Under Contract $\mathrm{C}-482$ \\ by the \\ University of California \\ Scripps Institution of Oceanography \\ Prime Contractor for the Project
}

April 1984

W. A. Nierenberg, Director

Scripps Institution of Oceanography
M. N. A. Peterson

Principal Investigator and Project Manager

Scripps Institution of Oceanography 


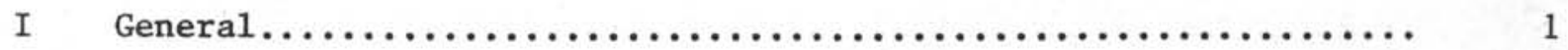

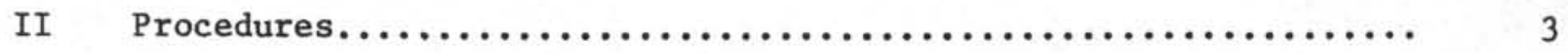

III Responsibilities, Key DSDP Personne1.................. 9

IV Global Marine Drilling Company

Operational Responsibilities-DSDP................... 17

$\mathrm{V} \quad$ Estimates for Scheduling of Operations................... 21

VI Coring, Drilling and Downhole Data Collecting Equipment.............................. 25

VII Coring Various Types of Formations with Rotary Coring Assembly........................... 33

VIII Coring Various Types of Sediment Hydraulic Piston Corer........................... 35

IX Coring Various Types of Sediment Extended Core Barrel.............................. 37

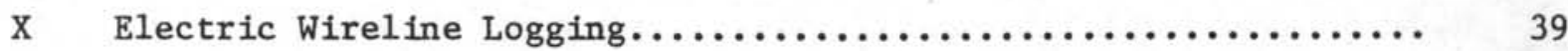

XI Reports - Operations............................... 41

XII Operational Capabilities of the

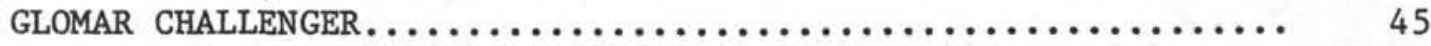

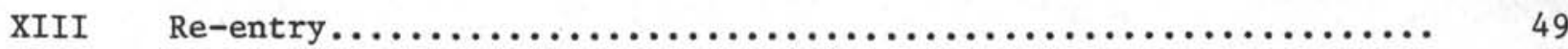

XIV Pollution Prevention and Safety....................... 51 


\section{ILLUSTRATIONS AND APPENDICES}

Fig. 1 DSDP Organization Chart, Fiscal Year $1984 \ldots \ldots \ldots \ldots \ldots \ldots \ldots$. 53

Fig. 2 Round Trip Time, Drill String.................... 55

Fig. 3 Wireline Trip Time, Core Barrel.................. 57

Fig. 4 Estimated Time On Site, Single Bit Holes............... 59

Fig. 5 Estimated Re-entry Time........................ 61

Fig. 6 Speed vs Shaft RPM, GLOMAR CHALLENGER................. 63

Fig. 7 Wireline Coring System................................. 65

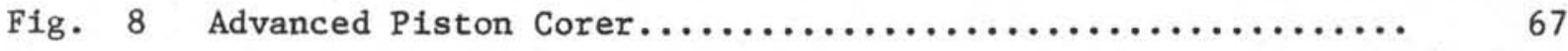

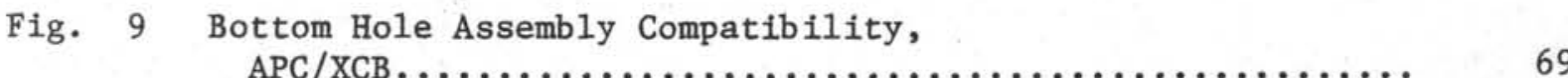

Fig. 10 Extended Core Barrel......................... 71

Fig. 11 Wireline Pressure Core Barrel...................... 73

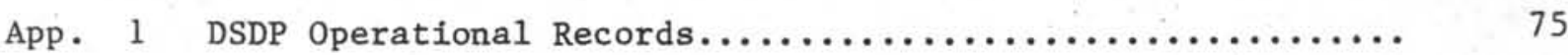


INTERNATIONAL PHASE OF OCEAN DRILLING

DEEP SEA DRILLING PROJECT

OPERATIONS PLAN

I. GENERAL

This plan is based on the operational objective of the Project, which is to drill and core sediments and basement rocks in the deep oceans and adjacent seas. Preliminary core description performed by the scientific staff aboard the vessel, and the normal maintenance by Global Marine Drilling Company performed on both the drilling vessel and on the equipment, are not included. In addition to drilling, coring and downhole geophysical experiments, the project conducts oceanographic operations, such as magnetometer surveys, depth profiles, and seismic surveys using air guns. These oceanographic operations are conducted whenever possible while the vessel is in transit. The information obtained is used for optimum site selection for drilling and coring. Survey equipment is not used during drilling and coring operations; however, sonobuoys are sometimes used in conjunction with the air guns for on-site refraction work.

Drilling and coring operations are the responsibility of the Scripps' Cruise Operations Manager. He works in close liaison with the Cruise Co-Chief Scientists who are responsible for the site selection and for the allocation of ship time to best achieve the scientific objectives of the voyage.

This plan is a guide. Experience has demonstrated that flexibility is required to achieve maximum results.

The Deep Sea Drilling Project makes every effort during planning and site surveying work to minimize any exposure to hydrocarbons and attendant hazards. If operations are continued in the presence of small amounts of methane gas and/or petroliferous odor, the hole will be continuously cored and a gas analysis and fluorescence check made on each core before proceeding. Operations will be stopped if a significant increase occurs in the proportion of ethane with respect to methane (even when relatively small amounts of gas are encountered) or if no core recovery is being obtained. In no case will operations continue if heavier hydrocarbons are found. See the JOIDES Safety Manual for more detailed guidelines. 
A. General

As soon as GLOMAR CHALLENGER is under way, precision depth recorder, air gun, seismic and magnetometer profiling equipment are rigged and operated by SIO personnel as directed by the Lab Officer and the Cruise CoChief Scientists. Due to the high hourly cost of the drilling vessel, these surveys are normally run at full speed. Better records are obtained at slower speeds, but this type of record is usually required only for the final site selection. In most areas, preliminary profiles conducted by smaller oceanographic vessels equipped with satellite navigation allow CHALLENGER to run a profile over the proposed site to confirm the location and bottom condition and to commence work immediately. A minimum of 100 meters of soft sediment is normally required to provide adequate lateral support for the drill string. This support is necessary to prevent excessive loss of equipment. Departure from this procedure will be attempted only when the Cruise Operations Manager has determined (after consultation with Co-Chief Scientists, Global Marine Drilling Co., and the weatherman) that: (1) the minimum soft sediment cover is absent in the area of interest; (2) the site has a high scientific priority and; ( 3 ) there is a reasonable chance of obtaining the desired information.

Before arriving at a coring site, a meeting of operational and scientific personnel is held. At this meeting the Co-Chief Scientists describe the site, what they expect regarding sediments, and what information they wish to obtain. A preliminary drilling and coring plan is reviewed.

The final approach to the coring site is normally made with the vessel traveling at six knots or less and the positioning beacon ready for immediate launching. The profiling is monitored by the Co-chief Scientists who determine the final drop point. As the vessel passes over the site, the beacon is dropped and allowed to free-fall to the seafloor. While it is falling, the profiling equipment is brought aboard and stowed, and the vessel turns back toward the drop points. When the beacon signal has been acquired, the positioning hydrophones are lowered to the operating position. The positioning system is then locked onto the beacon signal and checked for reliable operation.

As stable positioning over the beacon is established, preparations are made for running the core barrel and bottomhole assembly to the seafloor. The bottomhole assembly most commonly used consists of a 2-7/16" $x$ 9- 
7/8" roller cone core bit, one 8-1/4" O.D. core barrel, three 8-1/4" O.D. $x \quad 30^{\prime}$ drill collars, one $5^{\prime}$ stroke bumper sub, * three 8-1/4" x 30' drill collars, two $5^{\prime}$ stroke bumper subs, two 8-1/4" x 30' drill collars, one 7-1/4" $x$ 30' drill collar and two joints of 5-1/2" 24.70 lb range 3 drill pipe. Five inch 19.50 lb S-135 drill pipe extends to the surface. If hydraulic piston coring is to be done, a $3.80^{\prime \prime} \times 11.50 "$ bit and special core barrel adapter subs are used. This configuration also permits deployment of the extended core barrel (XCB) system--usually for coring beyond the maximum depth of the piston corer. Heavier BHA configurations may be used for coring hard rock or abbreviated assemblies may be run where only softer sediments are to be cored.

The drill string is then run to within about 20 meters of the seafloor as determined by the precision depth recorder and corrected to the particular operating area of the site.

To assure the best available water depth information and to avoid the possibility of "running into" the ocean floor with the drill string, at least two independent readings of the precision depth recorder will be made. One reading will be made by the scientific party and one reading will be made by the cruise Operations Manager. The Cruise Operations Manager will ensure that any discrepancies are worked out.

At this point the heave compensator and the power sub and swivel are picked up and attached to the traveling block. Drill pipe is added to the drill string as coring operations commence. The exact depth of contact with the seafloor is often difficult to detect, especially in very soft sediments.

If a mudine core is desired, the drill string is lowered until the bit starts to "take weight" or until it is believed that the inner core barrel contains sediments. The inner core barrel is pulled and the core is removed. The remainder of the hole is then cored (para. VII) and drilled as required.

Drilling mud (fresh water bentonite) and crosslinked guar gum (mixed with seawater and borax) are used to assist in hole cleaning, such as when chert or basalt chips are sloughing. No mud treatment chemicals are provided. However weight material is carried aboard the ship. Its use is restricted to abandonments as

* Two bumper subs are used in this position under certain operation conditions. 
barite (BaSO4) contaminates cores for some studies and can only be carried in limited quantities on the vessel. The hole may be filled with gel mud if required for certain types of open-hole logs.

After total depth has been reached, it is normal to release the bit on bottom using a hydraulic disconnect. This then provides a 3-15/16" bore. The drill string is pulled up to a point where its end is located at the uppermost competent formations. A suite of electric wireline logs is then recorded.

When site operations are completed, the hole is abandoned in accordance with the JOIDES Safety Panel's recommendations and the drill string is pulled. When all equiment is secured on deck, the vessel moves on to the next site.

\section{B. Measurements}

Drill pipe measurements in meters, as referenced from the elevator support bushing on the rotary table, are used to report the depth of the ocean floor and all coring depths. This support bushing is located 10 meters above sea level on GLOMAR CHALLENGER and 16 meters above the keel.

Upon arrival at a site, the depth of the ocean floor will first be established tentatively by the Precision Depth Recorder (PDR) which is corrected to the particular area of operation and then to the support bushing. Depths of penetration are measured from drill string lengths added after spudding. Operational reports will reflect drill pipe measurements in meters, with depths from the support bushing. Many scientists prefer to work with depths below seafloor, which results in a duality of depth records.

The Cruise Operations Manager will report all drill pipe measurements to the Cruise Co-Chief Scientists and make any adjustments required as a result of a review of the information available.

Drill pipe measurements used in reaching the ocean floor will be obtained by rack measurements of the entire drill string with a steel tape when significant quantities of new pipe are placed in service and on the first pipe trip following each crew change. Each joint added for coring and drilling is measured separately.

Where a closer correlation is desired between the drill pipe measurement of the seafloor and that recorded acoustically by the precision depth recorder, a drill 
pipe beacon can be used. A positioning beacon with the frequency altered to $12 \mathrm{kHz}$ is attached to the drill pipe about 100 to 200 meters above the BHA and is used in conjunction with the PDR. (It must be situated higher above the bit than the expected penetration).

C. Unstable Holes

Pelagic sediments (clays, oozes, chalks) of the deep ocean areas, have been found to be quite stable, and the Project has encountered very little difficulty with respect to holes sloughing, drill pipe sticking, etc. The major exception in the pelagic environment occurs when thin strata of intercalated cherts in soft oozes are encountered. Fragments of chert apparently become dislodged from the side of the hole, fall down and wedge the bit.

Similar problems are often encountered when penetrating basalt. Zones of basalt rubble are sometimes found at basalt-sediment interfaces (especially in areas of high basement relief and in young basalts). Basalt flows are often composed of shattered volcanic glass and pillow lava zones which may be subject to sloughing and wedging behavior.

When sediments of continental influence are encountered, such as unstructured, poorly indurated coarse turbidites and unconsolidated sand strata, severe sloughing and fillup problems may be experienced. Caution should be used in these situations.

Penetration of overpressured/underconsolidated zones may result in severe hole-cleaning problems when sloughing or flowing sediment "packs off" around the drill collars. The resultant rise in annulus pressure from the mud pumps then forces circulation into the weak zone and cuttings cannot be removed. Such conditions have been encountered in areas of high sedimentation rate and in thrust fault zones.

If the drill pipe becomes temporarily stuck or if severe torque conditions exist, drilling will be terminated. Drilling will proceed only when the Cruise Operations Manager, after consultation with the CoChief Scientists and Drilling superintendent, has determined that there is a reasonably good chance of achieving important scientific goals and that steps are being taken to minimize the risk of losing drilling tools.

If unstable hole conditions are encountered, the following actions will be considered: 
1. Circulate a slug of unweighted gel mud/guar gum to clean the hole of cuttings and slough.

2. Pull above the mudline, of fset the ship about 1000 feet and redrill.

If the pipe becomes stuck and cannot be worked free in a reasonable period of time, it will be necessary to disengage the pipe with the drill pipe severing system at a point above the point of sticking and to abandon the hole. If weight indications show bumper sub action, the bottom hole assembly is severed in the lowest free bumper sub. Otherwise the drilling history of the hole must be considered and a severing point in the free drill pipe is chosen. A free point indicator tool is carried on board for this purpose. The severing tool is run on the logging wireline. Positive depth control is by means of a casing collar indicator, and it is correlated with the driller's pipe tally for location of tool joints, bumper subs, etc.

The drill pipe severing system is critical to the DSDP operation as it provides the only means of recovering the majority of the drill string if drilling tools become irretrievably stuck. It is standard procedure to test the mechanical and electrical integrity of the severing tool and electric wireline winch once each leg by the following procedure:

1. Wiring up a dummy charge (less severing charge) with detonating cap and two feet of prima cord.

2. Rigging up and running of the severing tool into the drill pipe at least 1000 meters and firing the dummy charge.

This test may be performed any time sufficient drill pipe is suspended. It requires about three hours time. It is generally deferrred during voyages on which the winch is used for logging or re-entry operations.

\section{Personnel}

Cruise Operations Managers are normally full-time members of the DSDP Operations or Development Engineering staffs. However, Cruise Operations Managers occasionally are acquired from the petroleum industry on an invitation basis to enable the Project to make maximum use of current industrial developments and to share with industry the results of the technology developed by the Project.

Electronics Technicians are members of the Project 
Operations staff and, while at sea, report to the Cruise operations Manager. They are responsible for the maintenance and repair of University-owned electronic and electrical equipment. This includes laboratory, navigational, and downhole equipment. At least one Electronics Technician is aboard for each cruise and two technicians are normally required when re-entry operations are planned.

A Special Tools Technician/Engineer may be included on voyages featuring extensive downhole instrumentation, drill string packers, new coring systems, etc. He also reports to the Cruise operations Manager.

Logging engineers and technicians and other third party contractor personnel sailing in support of operational efforts report to the Cruise Operations Manager. Log interpretation or other reporting having direct scientific relevance is under the direction of the Co-Chief Scientists.

An organization chart of the Deep Sea Drilling Project is included as Figure 1. 
III. RESPONSIBILITIES - KEY DSDP PERSONNEL

A. Cruise Operations Manager

1. General

The Cruise Operations Manager is the senior employee of the Deep Sea Drilling Project of the Scripps Institution of Oceanography on the vessel and is responsible for all matters affecting the technical and operational success of the entire expedition. He plans, directs, and supervises the activities of Global Marine Drilling Co. through their designated supervisor and is charged with the responsibility of ensuring that the best possible techniques, equipment, and work efforts are being utilized.

He must exercise tact and judgment in his working relationships with the Co-Chief Scientists, the operating personnel, and the ship's Captain in order to ensure a highly efficient team effort.

The Operations Manager, after consultation with the Co-Chief Scientists and appropriately designated Global Marine Drillng Co. personnel, will designate to the Captain the times at which the Prime Contractor will be ready for departure from drilling sites and from ports.

He is authorized to expend funds for the Prime Contractor's equipment, supplies, and services; including repairs in ports of call as necessary, and under the direction and approval of the Manager of Operations.

He is responsible to see that all Prime Contractor personnel are aware of and adhere to the safety regulations of the subcontractor.

The Cruise Operations Manager is responsible for the execution of the recommendations and procedures made by the Safety and Pollution Prevention Panel of JOIDES and as approved by the Deep Sea Drilling Project. It is the Cruise Operations Manager's obligation, after consulting the CoChief Scientists, to terminate drilling operations whenever necessary to prevent any possible release of hydrocarbons. He will direct filling the hole with mud and/or plugging it with cement, as recommended by the Safety Panel. Final authority to terminate drilling resides with the cruise operations Manager. 
a) Represents the Deep Sea Drilling Project of the Scripps Institution of Oceanography (DSDP/SIO) in all operational matters. Has the responsibility of maintaining operations within the limits of the Program Plan.

b) Represents DSDP/SIO on the drilling vessel to the subcontractor GMDC. Coordinates drilling or taking cores with the drilling equipment.

c) Is responsible for the replacement and use of the expendable drilling and coring supplies furnished or replaced by DSDP/SIO.

d) Is responsible for seeing that the drilling equipment and the crews who operate the drilling equipment perform in a satisfactory manner for maximum core recovery with minimum risk or loss of the equipment.

e) Carefully reviews equipment maintenance and replacement. Reports any problems.

f) Checks and approves drill string components, maintenance, and replacement.

- Drill pipe inspection and grading

- Drill collar inspection

- Core Barrel and bumper sub maintenance

g) Represents DSDP/SIO in determining acceptable drilling conditions.

h) Reviews and signs all daily reports pertainilng to drilling, coring, or ship operation/maintenance from the subcontractor, as to completeness and correctness. Reviews, signs and forwards all receipts furnished by GMDC for equipment for which reimbursement will be sought. Approves in writing all overtime for GMDC personnel which is to be reimbursed by DSDP.

i) Represents DSDP/SIO in matters pertaining to discipline of the subcontractor's marine or drilling crews and of the scientific party.

j) Responsible for keeping current the complete inventory of all DSDP/SIO furnished equipment related to coring/drilling. 
k) Represents DSDP/SIO for on-site changes in drilling and coring procedures and equipment changes.

1) Represents DSDP/SIO in determining responsibility for lost or damaged equipment.

m) Is responsible for complete and accurate reports of drilling, coring, and ship operation/maintenance and transmission of this information ashore.

Clears all outgoing message traffic originated by scientific and technical personnel.

3. While On Land - Reports to the Operations Manager

a) Analyzes drilling and coring reports and recommends improvements in procedures and equipment.

b) Participates in planning of future voyages in conjunction with science representatives. Prepares operating time estimates and recommends procedures and equipment to achieve scientific goals.

c) Assists in ordering and scheduling delivery of expendable supplies furnished by DSDP/SIO and relating to operations.

d) Assists in scheduling and budget modifications as may be required by program changes.

e) Maintains liaison with the drilling industry to remain current with industry practices and the application of same to operations.

f) Assists in preparing reports required by the National Science Foundation.

B. Co-Chief Scientists

1. General

Responsible for the scientific success of the entire expedition, they have complete responsibility and authority for the optimum utilization of the vessel's time, except as abridged by the Program Plan and/or laws of the sea.

They are charged with the responsibility of 
following, so far as possible, the Drilling and Coring Program as recommended by the site selection panels of JOIDES, as reviewed operationally by the Project Chief Scientist and approved by the Project Manager and Principal Investigator.

2. Operational \& Specific

The Co-chiefs may change the site schedule or locations of sites at their discretion for reasons of: (1) scientific discovery (2) inadequate drilling or coring (3) ship's schedule or (4) weather. Single site changes are shipboard decisions and the Project Chief Scientist will be notified. Major changes of plans that grossly change the scope of the leg will be made only after the concurrence of the Project management. Additions of sites in areas where the possibility of hydrocarbon reservoirs exists will be done only if there is sufficient geophysical information available on the drilling vessel to choose a safe site. In addition, consultation with DSDP Headquarters and the JOIDES Safety Panel is required. (See also Program Plan Policy on departures from the Program Plan).

They are charged with the responsibility of working closely with the Cruise Operations Manager and the Captain to assure the success of the drilling operation.

They should notify the Operations Manager of any evidence found in the study of cores that might influence decisions on methods or rates of drilling or coring, or on continuation of drilling or coring.

Normally there will be two appointed Co-Chief Scientists. If there is only one, he shall designate in writing his alternate from among the other shipboard scientists, before sailing, who will assume his duties in the event he should become incapacitated.

They will specify to the operations manager the drilling sites to be occupied and the depths of drilling at each site and also the desired depths and extent of coring at each site. Their authority in this matter is subject to the capabilities of the drilling equipment, the ship's operational safety, and the health or safety of personnel on board. 
They will notify the operations manager when the scientific party will be ready for departure from drilling sites and from ports.

They will coordinate the scientific personnel and work aboard ship and will maintain good order and adherence to safety regulations within the scientific staff and technical staff.

They are responsible for determining the adequacy of laboratory equipment and supplies, and for specifying the need for expenditures for scientific equipment, supplies, or repairs in ports of call to the Project Chief Scientist, or to the Project Logistics officer.

They are responsible for presenting the information generated by the expedition in the following manner:

a) A preliminary report to be completed before departing the ship; this to be forwarded to the Project Chief Scientist for immediate distribution to scientists who will be working on the data.

b) Samples and associated information to be forwarded as specified in the shipboard manuals.

c) Initial core descriptions to be prepared under their supervision.

They are charged with the responsibility of ensuring that the sampling and measurements specified in the shipboard manuals are accomplished. In the event of problems, they will follow closely the contingency plans set forth.

All news releases or statements of scientific discovery shall be forwarded to La Jolla for release by Project Management after clearance by the National Science Foundation.

All data, preliminary reports, samples, and any other information pertaining to the expedition shall be delivered to the Deep Sea Drilling Project for distribution to various laboratories on shore.

It is the joint responsibility of the Cruise CoChief Scientists and Cruise Operations Manager to make every effort to avoid risks associated with encountering hydrocarbon accumulations. The Cruise Co-Chief Scientists will notify'the Cruise 
Operations Manager immediately if any petroleum stain, fluorescence, or readily discernible amounts of extractable hydrocarbons, petroleum odor, or natural gas is noted on any samples recovered. They will assure that all sites have been reviewed by the Safety Panel and that the recommendations of the Safety Panel are followed. A thorough survey will be made on sites where the possibility, however remote, exists of structural closure.

\section{Laboratory officer}

1. General

While at sea, the laboratory officer is responsible to the Cruise Co-Chief Scientists for the direct supervision and performance of the Project technical staff in the collection, recording and preservation of core material and geophysical and satellite navigation data and for the proper operation and maintenance of the ship's laboratories and related equipment. In normal practice he will direct and supervise these activities in a way consistent with the guidelines and overall priorities, policies and assignments made by the Project Chief scientist. He is a technician with extensive sea experience who is well familiar with relevant marine technology.

The laboratory officer works with GMDC through the Cruise Operations Manager when his areas of responsibility involve ship's personnel, equipment, or operations.

2. Specific Duties

a) Directly supervises the technicians aboard the vessel except for Electronics and special Tools Technicians.

b) Is responsible for the efficient operation of all laboratories on board the vessel.

c) Instructs and/or supervises the training of new technicians in the methods, procedures, performance, and handling of scientific instruments, equipment, lab facilities and data. Plans and assigns work schedules with priorities. 
d) Initiates and maintains quality control and safety methods in the areas of data collection, reduction, and filing to include sample analysis, handling, and preservation.

e) Maintains a shipboard inventory and is responsible for all shipboard scientific equipment and supply items. Responsible for all resupply orders for laboratory and associated supplies sent by radio.

f) Prepares all samples, data, and equipment, including necessary paper work, for return shipment to DSDP-SIO.

g) Affects repairs and modifications to the shipboard laboratories, instrumentation, and equipment within the resources available. Plans and/or suggests more extensive changes to be done during port calls.

h) He is directly responsible for the morale, conduct, safety, and efficiency of the technical staff.

i) Performs all necessary DSDP administrative requirements, including timekeeping for sio hourly personnel.

Authorization of overtime pay for DSDP-SIO personnel requires written justification and concurrence by the Lab officer, Cruise Operations Manager and Cruise DSDP Staff Representative.

\section{DSDP Staff Representative}

1. General

The DSDP Staff Scientists reports directly to the Project Associate Chief Scientist. While aboard ship he will acquaint scientists with the operation and capabilities of shipboard facilities, and stress the need for performing all necessary core descriptions. In addition, he will inform them of the philosophies and policies of the DSDP regarding: (1) format and content of published materials; (2) data forms and (3) procedures which should be followed.

2. Specific

His on-board responsibilities will also include 
making preliminary evaluations and descriptions of core materials in preparation for the Initial Report and participating as a full scientific member of the team.

Following the cruise, he will submit to the Associate Chief Scientist any suggestions for changing or modifying the systems, procedures, and formats used on the ship.

While on shore, he will serve as the scientific focal point at DSDP for the Initial Report volume for each cruise leg in which he participates. 
IV. GLOBAL MARINE DRILLING COMPANY

OPERATIONAL RESPONSIBILITIES-DSDP

A. Management

While at sea, the Captain represents GMDC and has overall operational responsibility for work performed by them including drilling.

It is the responsibility of Global Marine Drilling Co.'s Drilling Superintendent to implement drilling, coring and logging procedures that are best suited to the particular operation pending. The requirements of each location will be presented to Global Marine Drilling Co. by the Deep Sea Drilling Project's Cruise Operations Manager and Cruise Co-Chief Scientists at a pre-site meeting. The meeting will be held at a convenient time so that the Captain, Drilling superintendent and foreman, drillers, and service company representatives are given ample time to make either normal and/or special preparations for pending operations.

B. Coordination of Vessel Logistics

Initial estimates of resupply quantities will be provided by the shipboard storekeeper to the GMDC Operations supervisor at each port call. The supplies will be shipped ahead to successive ports of call via ocean freight in care of a shipping agent. Through daily reports consumption rates will be analyzed and the results used to define required quantities. Should a shortage at the next port of call be indicated, additional supplies will be dispatched as required. It will be the responsibility of the Global Marine Operations Supervisor to maintain records and coordinate the resupply function.

C. Maintenance Schedule

GMDC is to maintain both its own equipment and that SIO equipment specified in Exhibit "A" of the Subcontract in accordance with good drilling and marine practice, and/or in accordance with the GMI preventive maintenance program. When possible, maintenance activities will be scheduled in a manner that will not sacrifice operating time. When time must be scheduled for maintenance activities, either in port or under way, GMDC will notify the Project as far in advance as possible so that operating schedules may be brought into conformance. 
D. Maintenance and Inspection of Drilling Equipment

1. Drill Collars

The connections of all drill collars and subs will be magnafluxed every two months, or more frequently if conditions dictate. GMDC provides equipment and trained personnel for this purpose.

2. Drill Pipe

a) Inspection of drill pipe will be performed in accordance with API Recommended Practice $7 \mathrm{G}$ dated April 1974 at intervals no greater than six months and more frequently if dictated by field conditions. The top pup joint is to be magnafluxed at least once each month and replaced as required. Any defective part of the drill string will be removed from service promptly. Any drill pipe not meeting Premium classification will be taken out of service.

b) An internal sonde magnetic flux leakage device will be used during scheduled port calls to identify suspect joints. Trained third party operators will be used. These suspect joints will be further inspected by the drilling crews using a borescope and ultrasonics. Grades 2, 3 and 4 pipe will be removed from service and taken off the ship. Only premium grade and new pipe will be used in the drill string.

3. Load Handling Equipment

Load handling equipment is to be inspected daily, quarterly, and biennially in accordance with API Recommended Practice $8 B$ (for hoisting equipment) dated March 1963 with repairs effected accordingly. Inspections using magnaglo should be conducted at shorter intervals if conditions warrant. If possible, these inspections should be conducted in a suit able equipped shop and should involve disassembly and thorough cleaning.

Records will be kept on individual pieces of equipment as set forth in section 4 of Recommended Practice $8 \mathrm{~B}$. 
4. Bowen Power Sub

The load bearing component (stem) of the power sub is to be treated as hoisting equipment and magnafluxed at least twice a year.

5. Wireline Equipment

Rotary drilling lines and coring sandlines will be handled in accordance with the minimum standards set forth in API Recommended Practice $9 \mathrm{~B}$, dated December 1972. A record of cumulative sandline trips will be maintained for the purpose of replacing worn line.

E.

Method of Recording and Reporting Losses of and Damage to Government Property and

"Below the Keel" Equipment

All equipment losses and damages will be recorded in the driller's daily tour sheet and/or the ship's log. An equipment failure report form currently in use by Global Marine will be submitted to the Cruise operations Manager if applicable. Such damage or loss will also be reported by radio as an item of the operational hole summary.

F. Inventory

A running inventory of SIO coring equipment, bits and beacons, and of equipment below the rotary table, as described in Article 21-B of the Subcontract, will be maintained. An updated computer inventory printout will be submitted by the offgoing Cruise operations Manager to the Project and to the oncoming cruise Operations Manager at each GMDC crew change. In addition GMDC management will provide the DSDP Operations Department with a report concerning the status of procurement at the end of each leg regarding all equipment inventoried below the contract quantity set forth in Article 21-B, and other equipment on order as appropriate. 
A. Round Trip Time

Includes all operations from the start of pipe operations (normally when the vessel begins the automatic positioning mode) to "spud-in"; and from "last core aboard" to "pipe on deck" (see Figure \#2). A standard BHA configuration is assumed.

B. Coring Time

Includes all operations in the routine coring cycle for rotary or hydraulic piston coring with the exception of actual rotating time in the rotary mode (see Figure \#3). Actual rotating time for a 9.5 meter core ranges from five minutes in soft oozes to nine hours in very dense basalt. Wireline trip time is now virtually the same for the rotary and hydraulic piston coring systems due to improvements in shipboard handling techniques and design improvements.

C. Drilling Time

In some cases it may be desirable to drill ahead through previously cored intervals. In soft to semiconsolidated formations, rotating time is less than that required for coring due to improved bit hydraulics resulting from higher circulation rates.

In igneous rock and well-indurated sediments, it is necessary to core continuously as the core is not destroyed by hydraulics and slows drilling.

Sediment intervals are normally drilled with a standard inner core barrel in place, but center bits are available for use under certain circumstances.

D. Site Time

Figure 4 is included as a general planning guide for single-bit DSDP holes under normal conditions. It is based on historical data and allows for only minimal and predictable lost motion such as minor equipment breakdowns, an occasional extra wireline trip, etc. No allowance is made for special instrumentation runs, weather delays, stuck pipe or lengthy mechanical downtime.

E. Re-entry Sites

1. Exploratory Hole

The initial hole on a re-entry site is drilled to 
confirm the desirability and feasibility of the re-entry operation. It is necessary to sample sediments to determine their ability to support the re-entry cone and the casing string. The exploratory hole is cored as deep as possible to determine if unstable hole or other relatively shallow conditions exist which would preclude a deep re-entry penetration. This also determines whether the scientific objectives can be achieved without the commitment of time and resources to a re-entry project. Operating time for the exploratory hole is normally one to two hours longer then for a standard single bit hole because of a test conducted to determine if enough soft sediment is present for jetting in the conductor casing.

2. Running Conductor Casing and Cone

Fourteen hours, in addition to normal trip time (long casing strings will take somewhat more time).

3. Additional Casing strings

Techniques and hardware have been developed to deploy and cement into place a second (surface) casing string. A minimum of two days must be allowed for this casing string and considerably more time may be required due to the complexity of the operation.

4. Each Re-entry

Figure 5 is a guide to the average time consumed in actual re-entry operations. Note that scan time may take from five minutes to several hours. This is in addition to normal trip time and time to run the bit to total depth (varies greatly with hole conditions).

E. Hole Plugging Time

About one hour is normally required to fill a borehole with weighted mud for abandonment. Slightly more time may be required for very deep holes or holes in very deep water. Two to three hours should be allowed for cementing operations on those holes requiring cement plugs. 
F. Cruising and Profiling speeds

1. Maximum: $10+$ knots (see Figure 6). (wind assisted)

2. Average speed made good: $8-5$ to 9.0 knots 
VI.

CORING, DRILLING AND DOWNHOLE DATA

COLLECTION EQUIPMENT

A. Rotary Coring System

A modified Hycalog wireline core barrel is the primary coring tool for the Deep Sea Drilling Project (see Fig. 7). This design uses a drill collar as the outer barrel. These collars are the same as those used in the bottomhole assembly. The design places an inner barrel support bearing near the bit. This removes the landing shock from the inner barrel swivel as used on top landing systems. Cores are cut by rotating and lowering the entire drill string. The cutters of the core bit and the circulation of seawater remove rock or sediment ahead of the bit, but leave a central stub which becomes the core. The core passes through the open throat of the bit and into the inner core barrel. This inner barrel retains the core by means of core catchers at the bottom and the core is retrieved through the drill pipe by means of a wireline.

This system can be used in virtually any sediment or crustal material with only minor modifications in equipment and techniques. Standard cores recovered are 9.5 meters long and about $61 \mathrm{~mm}$ in diameter.

B. Hydraulic Piston Coring System

A system combining the principles of oceanographic piston coring and stored drill string energy has been developed by DSDP for coring soft marine sediments. The system produces virtually undisturbed cores at a very high recovery rate.

The advanced piston corer (Figure 8 ) is the third generation hydraulic piston corer deployed on GLOMAR CHALLENGER. It combines advantages over previous systems of increased strength and penetration power, fewer parts and more efficient handling. Full 9.5 meter cores may now be taken from depths as great as $300 \mathrm{~m}$ below seafloor (although $100 \mathrm{~m}$ or less is typical). The APC requires a special seal bore drill collar as an outer core barrel which renders the BHA incompatible with the standard rotary coring system (above). It is, however, compatible with the newly developed extended core barrel ( $X C B$ ) system described below (see Figure 9).

In the piston coring operation, the corer is locked together by shear pins until it has been lowered into place at the bit by wireline. Upon landing, the seals of the corer seal off the bore of the drill string. 
Pressure is then applied to the drill pipe with the rig pump until forces resulting from differential pressure cause the shear pins to fail. The inner core barrel is thus forcibly ejected through the bit while moving past a fixed internal piston. A sliding seal against the bore of the outer core barrel maintains downward fluid pressure on the inner barrel until it reaches the end of its stroke. The extended assembly and the full inner barrel are then recovered with the wireline.

A more detailed treatment of hydraulic piston corer systems is found in DSDP Technical Reports Nos. 12 and 21.

\section{Extended Core Barrel System}

Core Recovery has historically been poor at DSDP sites where alternating sequences of hard and soft material were cored. This was at least partially due to the inability to adequately adjust downhole circulation rates to the frequent changes in formation properties. Soft material was often washed away or inadequate fluid flow caused harder, dryer core to jam as it entered the core barrel.

The extended core barrel (Figure 10) was therefore developed by DSDP wherein a spring-loaded cutter shoe extends beyond the bit to core soft material ahead of the disturbing influences of the fluid jets and the roller cones. The resistance of harder material causes the BHA weight to force the inner barrel upward, with the cutter shoe retracting to a position above the roller cones. This automatically restores full circulation to the point at which core is being formed. The inner core barrel (with cutter shoe) is driven by the drill string, but the plastic core liner is rotationally decoupled from the inner barrel.

Since both the $A P C$ and $X C B$ systems require a largediameter bit throat, an outer core barrel assembly has been designed that permits the corers to be deployed interchangeably. This provides the long-awaited option of changing from HPC to rotary ( $X C B$ ) coring at will or of returning to the HPC mode--all without a round trip of the drill string. The $X C B$ has successfully cored well-indurated sediments, but has not performed well in igneous rocks to date. Further development is planned in this area.

DSDP Technical report No. 20 covers the development and design of the XCB in detail. 
D. Pressure Core Barrel System

The study of natural gas hydrates and other geochemical research led to the development of a system that would recover cores at in situ pressure. A special core barrel, compatible with the standard rotary system, was designed for this purpose. A ball valve assembly was incorporated into the lower portion of the retrievable inner core barrel to close off the inner barrel chamber at the bottom. The ball valve and the vent at the top of the barrel are closed mechanically when the inner barrel is unseated for retrieval.

Because of the ball valve mechanism, the PCB cannot accommodate a full $62 \mathrm{~mm}$ diameter core. A special bit must be used that trims a reduced-diameter ( $54 \mathrm{~mm}$ ) core. Opting for the PCB capability on a given hole (or bit run) therefore means that all cores will be of the smaller diameter. Reverting to standard core diameter requires a round trip of the drill string.

The PCB is shown in Figure 11, and a more detailed description may be found in DSDP Technical Report No. 16.

E. Core Catchers

Two basic configurations of the DSDP dog-type core catcher are utilized in rotary coring operations. The soft formation version features ten dogs which operate to maximize closure of the inner core barrel bore. In very soft or granular formations capable of flow, a sailcloth "sock" is installed in conjunction with the soft formation catchers. The hard formation configuration utilizes eight dogs and stronger construction at the expense of gaps in the closure. Both versions of the dog type catchers are normally run in tandem.

The "flapper" type catcher consists of a full opening and closing cylindrical trapdoor arrangement. This is the most commonly used core catcher with the hydraulic piston core apparatus and has been used successfully as a substitute for the ten-dog catcher/sock combination described above.

Other types and modifications of catchers may be used as coring conditions dictate. Specialized versions are used in the $X C B$ and the $P C B$.

F. Core Bits

Various core bit designs have been used, and development of new bit designs continues. The primary core bit now in use is the four cone roller cutter type with 
sealed journal bearings and tungsten carbide inserts (TCI). The inserts (or teeth) are rounded for the hardest rocks, and chisel-shaped and extended for softer formations.

Bits currently in general use include several variations of three major types distinguished by the inserts utilized. Insert length is denoted by the digits in the model designation as follows:

1. Type 93 - Long Chisel-Shaped Inserts

Is used where sequences of soft sediments and rocks of low compressive strength are anticipated; especially effective in shales, clays, marls and most chalks, but may be damaged if chert or basalt is encountered.

2. Type 94 - Intermediate Length Chisel-

Shaped Inserts

Has proved to be the most effective bit for general use and provides a good compromise in that it cuts both soft and hard formations about equally well. It is used where varied formations are to be encountered or where the lithology is not well known.

3. Type 99 - Very Short Hemispherical Inserts

The most durable bit for drilling formations of very high compressive strength, such as basalt. It is normally used in re-entry holes after basement has been reached. Other uses could include single bit basement holes where overlying sediments are soft enough to be washed away or where thick strata of sandstone or very hard limestone are to be drilled. This bit is ineffective in shaly, waxy or gummy formations.

4. Pressure Core Barrel Bits

Are identical to standard bits except that closer cone spacing and reduced diameter core guides produce a 2-1/8" (54 mm) core. Either Type 93 or Type 94 cones may be used.

5. $\quad$ HPC/XCB Bit

Uses Type 93 or Type 94 cones, but the entire body has been redesigned to provide proper hydraulics and support for both $H P C$ and $X C B$ operations. Dimensions are 11-7/16" outside diameter and $3.80 "$ throat diameter. The large throat diameter also 
G. Center Bits

The inner barrel may be easily modified for drilling ahead, however, experience has shown that the use of such a center bit assembly has been generally ineffective and time consuming. In soft formations, drilling ahead is accomplished with a normal inner barrel in place. By using full circulation, the core is washed away ahead of the inner barrel. When a core is desired, circulation is merely reduced or discontinued entirely. It must be recognized that, under these conditions, the depth from which core is recovered is not precisely known. In hard formations, faster penetration rates achieved by coring generally offset wireline time spent in retrieving cores.

H. Mechanical Bit Release

The requirement to pass logging and other instruments through the drill pipe and into open hole led to the development of bit release mechanisms. The core bit, float valve, lower support bearing and a modified bit sub are disconnected and left at the bottom of the hole. This leaves the pipe open-ended with a minimum inside clearance of $3-15 / 16$ inches.

The original (mechanical) bit release continues to be used in certain operational situations. A special shifting tool is lowered to the bit on the wireline. An internal sleeve is engaged and shifted upward as the tool is retrieved, actuating the release mechanism and permitting the bit and associated components to fall off.

I. Hydraulic Bit Release

In the hydraulic model (Figure 12), differential pressure is used to shift an annular piston and actuate the release mechanism. The differential is obtained by emplacing a go-devil (pumped down the drill pipe or run on the wireline) which seals the bore of the bit release and subjects one end of the piston to drill pipe pressure through ports in the bore, while the other end is vented to hydrostatic pressure below the seal. The bit and associated components are released and forced to detach when the drill pipe is pressured with the rig pump.

J. Core and Hole Orientation

A photographic "single-shot" well surveying device has 
been adapted for use with the HPC system to provide orientation of piston cores with respect to magnetic north. The direction and amount of hole deviation from vertical is recorded at the same time. The single shot may also be used to measure the degree of deviation from vertical in holes drilled with other coring systems.

The instrument is enclosed in a nonmagnetic pressure case which is incorporated in the sinker bar assembly directly above the retrievable coring apparatus. For HPC work, the instrument is keyed to a system of reference marks extending to the plastic core liner and the entire system is locked to prevent independent rotation at any point. The orientation reading is taken just prior to actuation of the corer when the instrument pressure case is located inside a special nonmagnetic drill collar in the BHA.

The system has not been consistent in providing usable data, and it has many operational and logistical disadvantages. A gyroscopic orientation system is currently under development to replace the single shot.

K. Heat Flow/In Situ Sample Probe

An instrumented inner core barrel has been developed that provides the capability of recording downhole temperatures and collecting an interstitial water sample on the same wireline run. The innner barrel is lowered on the wireline and latched into the outer core barrel with a sensor probe protruding through the throat of the core bit. The bit is lowered to the bottom of the hole and the weight of the drill collars pushes the probe into undisturbed sediment. The tip of the probe contains a thermistor and a pore water intake. At a preset time, a valve opens to allow fluid to flow from the sediment through the probe into a chamber inside the barrel. The valve closes after a predetermined interval and the entire instrument is recovered with the wireline. Temperature data are recorded automatically throughout the entire operation at 30 second or two minute intervals to a maximum of about 4-1/2 hours. The instrument may be held at any point in the cycle for temperature equilibration as required by science.

Certain risks are inherent in such instrumentation runs. Time spent on the bottom without rotation or circulation increases the risk of becoming stuck. Therefore probe runs should be made only when the hole is clean and in good condition. If sediments are too firm, there is danger of bending or breaking the probe. Since this can result in loss of the hole, the instrument probe should not be run in re-entry holes. An 
additional restriction is the requirement for the sediment to be sufficiently competent to support the weight of the lower stand of drill collars. If it is not, the probe will settle downward through the sediment and produce inaccurate temperature data due to frictional heat.

L. HPC Heat Flow Shoe

A self-contained temperature recording device has been developed for use with the hydraulic piston corer. The standard cutter shoe/core catcher assembly is replaced on data runs by a special two-piece assembly. Pressure-tight pockets in the wall of the shoe contain a small thermistor/electronics package and a battery. Temperature data are recorded (at preset time intervals) throughout the core run. only about a five minute delay is required for equilibration after actuation of the corer and before retrieval commences. On recovery, data may be read directly and plotted by computer.

M. Heave Compensator

The drill string heave compensator is used routinely in rotary coring operations to decouple the vessel's vertical motion from the drill string. This greatly reduces shock loading on the bearings of the bit, thereby increasing bit life. The compensator also permits temperature probe readings with reduced bit weight in soft sediments and improves deviation surveys by reducing drill string motion.

The compensator system maintains relatively constant weight on the core bit by acting as a hydraulic/pneumatic spring. The entire drill string is supported by the piston of a large hydraulic cylinder that is suspended from the traveling block in the derrick. This cylinder is connected by large hydraulic lines to a second (stationary) cylinder. The hydraulic pressure below the piston in this cylinder is balanced by a high pressure air bank piped to the top of the piston. The amount of drill string weight supported by the compensator can be varied simply by adjusting the pressure in the working air bank. 
VII. CORING VARIOUS TYPES OF FORMATIONS

WITH ROTARY CORING ASSEMBLY

The procedures for coring various types of formations are outlined below:

A. Slushy Unconsolidated Formations

Coring this type of formation requires only a punch core procedure. The drill pipe is lowered evenly and steadily without rotation, holding as closely as possible a constant bit weight. No fluid is pumped during this operation. Approximately six minutes is required to fill the inner barrel. Faster lowering of the drill pipe will result in poor recovery. To prevent the core sample from falling out of the barrel during retrieval, a sailcloth sock may be used. This sock is held in place by being inserted into the upper dog-type catcher. The sock extends about ten inches inside the plastic tube. When the core sample starts to fall from the tube, it crumples the plastic sock and forces it onto the dog-type catchers, trapping the sample inside the plastic tube. Two dog-type core catchers are used when coring this type formation. An alternative to the plastic sock is to substitute a "flapper" type core catcher for the dog-type catcher. This is the catcher normally used with the hydraulic piston corer.

B. Dry Unconsolidated Formations

When the sediment becomes drier, the plastic sock is no longer used. This decision is based on experience. The formation has to be dry enough and consolidated enough not to fall through the dog-type catchers. In coring this type of formation, the bit is turned slowly. The core is taken without fluid being pumped until the bit weight and torque is incrased to a point where it is necessary to pump fluid. Then the pump is started and circulation is "broken". At the instant circulation is broken, the pumps are shut off. During this time the bit is being rotated slowly with the weight on the bit as constant as possible. When the circulation is "broken", the penetration instantly increases and the above coring cycle is repeated.

C. Basalt or Very Hard Sediments

When this type of lithology is encountered, the hard formation core catcher assembly is installed on the inner core barrel.

A good bottom hole assembly for coring in this type formation has one lower bumper sub that will permit the bit to cut a pattern with light bit weights and at the 
same time maintain contact between the bit and the bottom of the hole. A successful procedure is to maintain this light contact for a brief period while turning at about 40 to $50 \mathrm{rpm}$. Then the bit weight is increased to about 35,000 lbs., moving the bumper sub action to a top bumper sub. Circulation rates do not appear critical to core quality, but must be sufficient for efficient removal of cuttings. 
VIII.CORING VARIOUS TYPES OF SEDIMENT WITH HYDRAULIC PISTON CORER

A. Capabilities

The hydraulic piston corer (HPC) was designed primarily for coring the soft material found in the upper 100 meters of the sediment column. The thickness of soft sediment varies greatly, however, and holes have been cored to as deep as 300 meters with good results while much less than 100 meters of suitable material was found in other locations. Good piston core penetration and recovery can be expected in material with vane shear strengths to $1200-1500 \mathrm{gm} / \mathrm{cm} 2$. Reduced penetrations and recovery are possible to a fairly high degree of induration before damage to the cutting shoe of the corer occurs. Sand, especially in the fine to medium size range, is extremely difficult to penetrate due to its incompressibility. Fairly good recovery of sand cores has been achieved, however, through the combined use of flapper, sock and standard core catchers.

B. Incomplete Recovery

With reduced recovery in harder formations or sand, the amount of wireline time required to recover an uninterrupted section increases in relation to the reduction in recovery. The bit is drilled down only to the depth corresponding to the bottom of the previously recovered core and the next core is "shot" from that point.

NOTE: Incomplete recovery does not normally result in lost section as in rotary coring.

A time-saving compromise is sometimes employed wherein the bit is drilled down a full 9.5 meter interval and the unrecovered section of the previous interval is sacrificed.

C. Variable Penetrating Force

The pressure required to extend the piston core barrel (and therefore the force with which it penetrates the sediment) may be varied by using from one to $3-1 / 2$ shear pins in a choice of two strengths. There is some indication that excessive penetrating force results in core disturbance in soft sediment and an effort is made to use only the amount of pressure necessary to achieve full penetration. As coring continues into more compacted material, cores are monitored closely for incomplete recovery or indications of flow-in disturbance (caused when the piston is pulled to the top of the barrel following an incomplete stroke). More or larger shear pins are then employed on subsequent cores to increase penetrating force. A breakaway piston head to prevent flow-in is under development. 
IX. CORING VARIOUS TYPES OF SEDIMENT EXTENDED CORE BARREL

The XCB system was designed to provide a degree of automatic compensation of fluid flow and drilling weight. Therefore, the coring operation is less dependent upon the parameters controlled from the driller's console. The system is still quite new, and weight, RPM and circulation guidelines are not yet established. Adequate circulation must be maintained to prevent the cutter shoe from "dry drilling", and there has been little or no problem with soft material washing away. In hard strata, the principal concern seems to be the regulation of weight and RPM to minimize damage to the cutting shoe.

The XCB can be run interchangeably with the advanced piston coring system, providing the BHA is set up properly. Normally HPC cores are taken to the point of refusal or until short cores consume excessive wireline time, and coring then continues in the XCB mode. The XCB may also be used for intervals with interbedded chert or other hard streaks, with HPC coring continuing in underlying soft beds. 


\section{ELECTRIC WIRELINE LOGGING}

It is standard procedure to survey holes of sufficient depth with a basic suite of open hole well logs. In most cases a long-spaced sonic velocity/dual induction/natural gamma ray/caliper run is made first. A second run through the open hole interval with this tool records a wave train log. The next run, with a different sonde, is a formation density/neutron porosity/natural gamma ray log.

With a few exceptions the logging tools are standard oilfield equipment and are supplied and deployed by a logging service contractor using the Project's MOHOLE logging winch and cable. The diameter of the tools (3-5/8" max) requires that they be run into the hole through open-ended drill pipe. On single bit holes, the bit and associated components must therefore be released and are left at the bottom of the hole. The drill string is then pulled until the bottom of the pipe is about 110 meters below the seafloor. Therefore the interval logged is from this point to total depth. On re-entry holes it is possible to re-enter the hole with open-ended pipe and to log with no effect on future operations.

While the formation density and neutron porosity logs are radioactive devices that have the capability of logging through drill pipe, experience has shown through-pipe logs to be of little value in DSDP holes due to the attenuated signal. Natural gamma ray logs have been useful in delineating alternating clay/non-clay beds through pipe where open-hole logging was not feasible.

Time consumed by logging operations varies greatly, depending on the number of logging tools to be run, depth of water and depth and condition of the open hole. Three to six tools are normally deployed per logging operation and four to eight hours per tool should be allowed, depending on depth. Experience has shown that an additional five to six hours is generally required for hole conditioning, bit release, rigging logging sheaves, tool malfunctions, etc. 


\section{REPORTS - OPERATIONS}

A. Daily Driller's Log

The API-IADC Daily Drilling Report is a standard form in which all activities of drilling personnel are recorded (including drilling payroll). This form is to be signed by the Cruise operations Manager and GMDC Drilling Superintendent.

B. GMDC Ship's Log and Engine Room Log

These logs constitute the subcontractor's record of ship's operating time, movement, weather, drills, marine crew payroll, fuel consumption, water distilled, and other aspects of the ship's operation of which the Cruise Operations Manager should be cognizant. Copies of these records will be provided to the Cruise Operations Manager on a daily basis.

C Daily Operations Report Wire

This is a Deep Sea Drilling Project form. The CHALLENGER's daily report to the Deep Sea Drilling Project and GMDC is received through SIO radio station WWD. It is to be signed by the Cruise Operations Manager and the GMDC Captain. The DSDP format for the body of the daily drill wire is as follows:

1. Date (drilling data is summarized for 24 hours preceeding 0000 hours on the date of origin).

2. Location or Site Number

3. Roll (degrees, half amplitude)

4. Pitch (degrees, half amplitude)

5. Water Depth (meters) if on station

6. Midnight Depth (meters total drill string) when on station; depth at time of transmission is usually given also.

7. Meters Cored; Meters Recovered; Meters Drilled

8. Bit Type (model designation)

9. Cruising Hours

10. Cruising Hours 
11. Breakdown or Downtime (hours)

12. Injuries

13. Remarks - includes any items of operational significance not covered or adequately explained under Items 1-12. First report on a new site should include latitude and longitude, prospectus designation, number of site, bottom hole assembly, beacon and bit serial numbers, etc.; also a brief update statement of status at time of transmission.

14. Heave Compensator stroke and hookload fluctuation.

D. Operations Hole Summary Wire

DSDP Form; technical summary of drilling operations to DSDP Operations Management. Includes technical problems and/or successes and equipment lost or consumeed (with serial numbers). To be signed by the cruise Operations Manager and submitted by radio within 48 hours after completion of each hole. Below is the DSDP format for the hole summary wire:

1. Hole Number

2 Best Latitude and Longitude Position (based on satellite fixes)

3 Total Meters Cored; Hours Spent Coring

4. Total Meters Cored Recovered; Percentage of Recovery

5. Total Meters Drilled; Hours Spent Drilling

6. Below the keel equipment lost or consumed (including serial numbers for bits and beacons).

7. Remarks (significant operational problems and/or successes, including hole problems, new or experimental equipment performance, condition of bit when pulled, etc.).

8. GMDC Drilling Equipment lost or consumed (bumper sub components sandlines, etc.).

E. Voyage Operations Resume

Summary of each leg's operational progress. Prepared by the Cruise operations Manager. Report is to be 
submitted within 20 days following the end of each leg. Resume to include: (a) breakdown of Time and Summary of Operations (leg commences when vessel arrives in port for resupply and ends when vessel again arrives in port for resupply); (b) Time Distribution Graph; (c) Beacon and Position Summary; (d) Bit Record.

F. Additional Reports

In addition to, and to aid in filing the above reports, the following are normally submitted to the cruise Operations Manager:

1. Coring records, submitted by the Coring Technician following operations at each site, includes meters drilled and cored, core recoverry and coring times, and drilling parameters such as bit weight, rpm, and pump pressure. In addition, the Cruise operations Manager may require a daily report to supplement the driller's log.

2. Beacon and positioning summary, submitted by the GMDC Electronics Technician following each site, includes beacons used and their performance, along with oscilloscope photography of the beacon pulse. Also included are comments on the performance of the overall positioning system for the duration of site occupancy.

3. Voyage Summary, submitted by the ship's Second officer at the end of each leg, includes steaming time, nautical miles traveled, and speed between sites and/or ports. A copy of the daily steaming report, which includes ship's position, may also be submitted to the Cruise Operations Manager. 
XII. OPERATIONAL CAPABILITIES OF THE GLOMAR CHALLENGER

A. Water Depth

The vessel can maintain station and operate during most weather conditions in water depth from about 900 meters to over 6,200 meters. Operations require that the vessel not move off location greater than $3 \%$ of water depth while rotating pipe or $5 \%$ while not rotating. The risk of losing the drill string due to vessel excursions becomes greater in water depths less than 900 meters.

B. Penetration

There are no upper limitations to penetration other than that imposed by hole stability and the limitation imposed by tensile strength of the pipe on the weight of the total drill string suspended.

C. Total Drill string

In calm weather the drilling equipment becomes fully loaded with a drill string of 6860 meters (allowing for $100,000 \mathrm{lb}$. overpull in case of stuck pipe). Operations have been carried out with a string in excess of 7000 meters on one occasion in calm seas. Experience has shown, however, that as these depths are approached, dynamic loading can reach $90 \%$ of the pipe's minimum yield strength with light to moderate swell conditions. Any drilling with a string longer than 6860 meters should be done only if sea/swell conditions are minimal and forecast to stay that way, hole conditions are good, the upper portion of the string is composed of new pipe and the "piccolo" drill pipe restraint is installed. Rubber drill pipe protectors or "knobby" drilling joints must be run at the top of the string. These guidelines assume the weight, of a standard DSDP BHA. If extra weight such as additional drill collars, re-entry cone, casing, etc. is carried, string length limitations must be adjusted downward accordingly. The contractual maximum string length is $25,000 \mathrm{ft} . \quad(7620 \mathrm{~m})$, but recent experience indicates that this is not a realistic operating depth for GLOMAR CHALLENGER'S present drilling system.

D. Operations During Severe Weather

The following operational limits and procedures have been established to protect personnel and equipment during severe weather conditions: 
1. Drill pipe shall not be run when anticipated sea conditions will cause the ship to pitch and/or roll in excess of seven degrees single amplitude."

2. Drilling operations, including running of drill pipe, may continue on the basis of a maximum pitch and/or roll of seven degrees single amplitude."

3. The drill string shall be pulled if occasional pitch and/or roll exceeds nine degrees single amplitude.

4. If personnel safety considerations require that pulling/running the drill string be stopped due to weather, a minimum of three heavy drilling joints should be picked up. Then the drill string should be slowly moved up and down over about a six meter interval so that the pipe located at the keel of the vessel is moved. Avoid having a connection within five feet of keel.

5. Positioning: When moving the ship with drill pipe extended, bending of the drill pipe shall be held to less than seven degrees as indicated by cutouts on the horn. During such operations, the drill pipe shall be moved vertically, frequently. The ship should not be moved at a speed greater than one knot and should be moved only as far as offset from a positioning beacon permits. Sufficient time must be allowed for the drill string to resume its generally vertical attitude before spudding.

6. If the presence of a strong current is indicated by the handling characteristics of the ship while positioning over the beacon on a new site, time should be taken to obtain a reasonably accurate estimate of current velocity before commencing to lower the drill string. If a current in excess of three knots or excessive drill string vibration is encountered, regardless of wind direction and speed, consideration will be given to the selection of another site.

If wind, current, and sea forces are combined in one direction, the ship can operate in up to 15 foot swells, 40 knot winds and 3 knot currents. However, where these forces are not in the same direction ( and wind or current may change direction on short notice), operations may have to be

Limitation is five degrees for drill strings

in excess of 6860 meters. 
E. Types of Ocean Floor Sediments Required for Drilling

A soft, easily penetrated sediment cover is required to provide lateral support to the bottom hole assembly when drilling operations are begun ("spudding in"). Ideally, this soft sediment cover is equal in thickness to at least the length of the drill collars in the bottom hole assembly and can be penetrated without rotation. Many connection failures have occurred in the past due to insufficient soft sediments and have resulted not only in the loss the equipment, but also a considerable delay in the coring program (on the order of two days per failure). Where existing profile records show a thin sediment layer (less than 100 meters) or where piston corer experience (shallow penetration) shows that the bottom is firm, additional time should be spent in making a detailed seismic survey of the area to optimize the amount of soft sediment cover.

Operations that are begun where the soft sediment cover is less than 100 meters must be carried on carefully. When there is adequate sediment cover to support the bottom hole assembly, operations normally move along much faster. The lower limit of sediment cover that a hole can be drilled in is normally considered to be 50 meters, which is sufficient to support the lower bumper subs. 
A method of making multiple bit runs has been developed and has been upgraded and altered somewhat during recent years. This technology is used in deep penetration holes and provides for longer casing strings and improved capabilities for handling drill cuttings.

Detailed procedures for re-entry operations can be found in DSDP Technical Report No. 2 .

Detailed information as to re-entry equipment can be found in Technical Report No. 13.

Re-entry is desirable only on those sites where deep scientific objectives merit the expenditure of time involved in the drilling of an exploratory hole and in the actual reentry operations. A guide to estimating the extra time involved is found in section $V$. 
A. General

The possibility of the uncontrolled flow of formation fluids into the ocean from core holes drilled under this program is a hazard unless recognized by appropriate caution and action. The GLOMAR CHALLENGER is not equipped with a closed circulation system for primary control nor with preventers for secondary control of blowouts. Therefore, fundamental control can be provided only through the interpretation of geophysical records to avoid closed structures of permeable formations. Drilling pelagic sediments and Layers 2 and 3 generally will be very safe.

B. Review of Sites

All sites are reviewed prior to the commencement of a leg by the JOIDES Panel on Pollution Prevention and Safety. The existing seismic profile records are reviewed to assure that the proposed sites will not be drilled on a closed structure. In addition the Panel advises the project on precautions to follow during coring operations and the proper abandonment procedures.

An additional review of proposed sites and the Safety Panel's recommendations is made by a panel of scientists at the Scripps Institution of Oceanography.

C. Safety Manual

The JOIDES Panel has prepared a manual for shipboard use which details precautions that should be followed on various sites. This manual is used in conjunction with the individual site recommendations, and it is the policy of the Project to follow the recommendations in the manual.

D. Abandonment

1. General

The GLOMAR CHALLENGER is equipped to fill a core hole with cement or with weighted drilling mud. Plugging is standard procedure for holes in which hydrocarbon shows are encountered and for holes drilled into consolidated sediments of continental margins.

The vessel is equipped with an oilfield type cementing pump and a continuous jet mixer for mixing and emplacing a cement slurry. Weighted mud 
is kept on hand in a liquid mud storage tank and is emplaced with the rig mud pumps.

2. Drilling Mud

The vessel is equipped with six 2,000 cu. ft. pneumatic tanks for the storage of dry materials as follows:

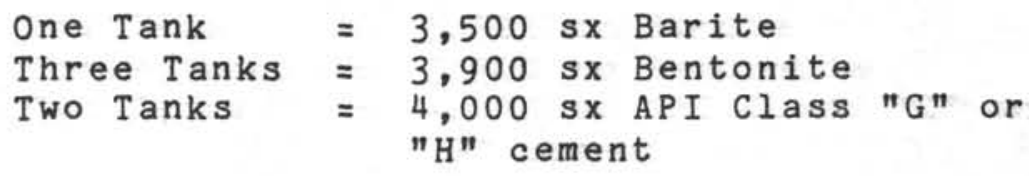

Unweighted mud is occasionally used to help lift cuttings and clean out core holes. Weighted mud 10-11 ppg (75-82 pcf) is normally used to abandon sites as recommended by the Safety Panel. Mud weights in excess of 12-13 ppg are incompatible with the ship's mud handling equipment. If higher fluid weights are desired for plugging, cement should be considered. 
FIG 1.

DSDP ORGANIZATION CHART, FISCAL YEAR 1984

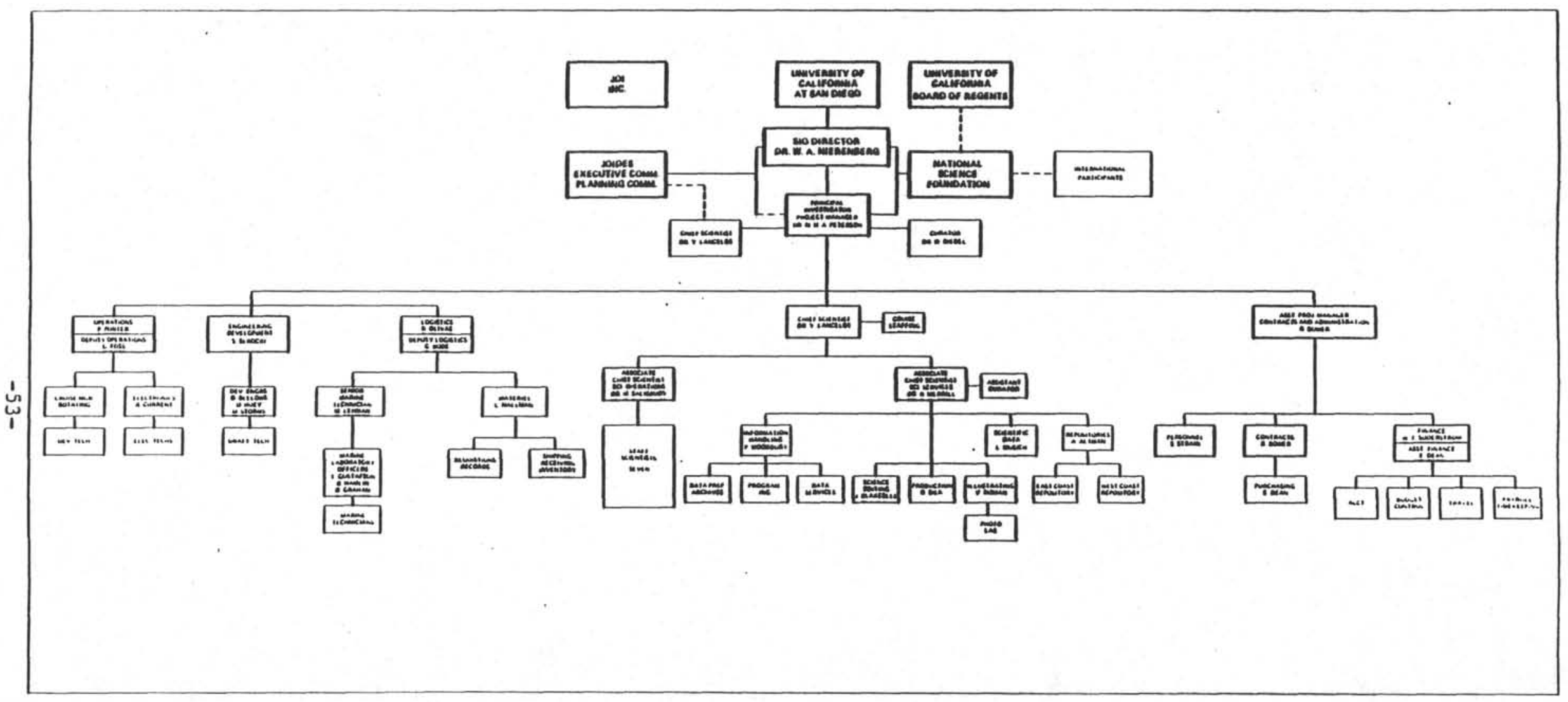


FIG 2

ROUND TRIP TIME,DRILL STRING

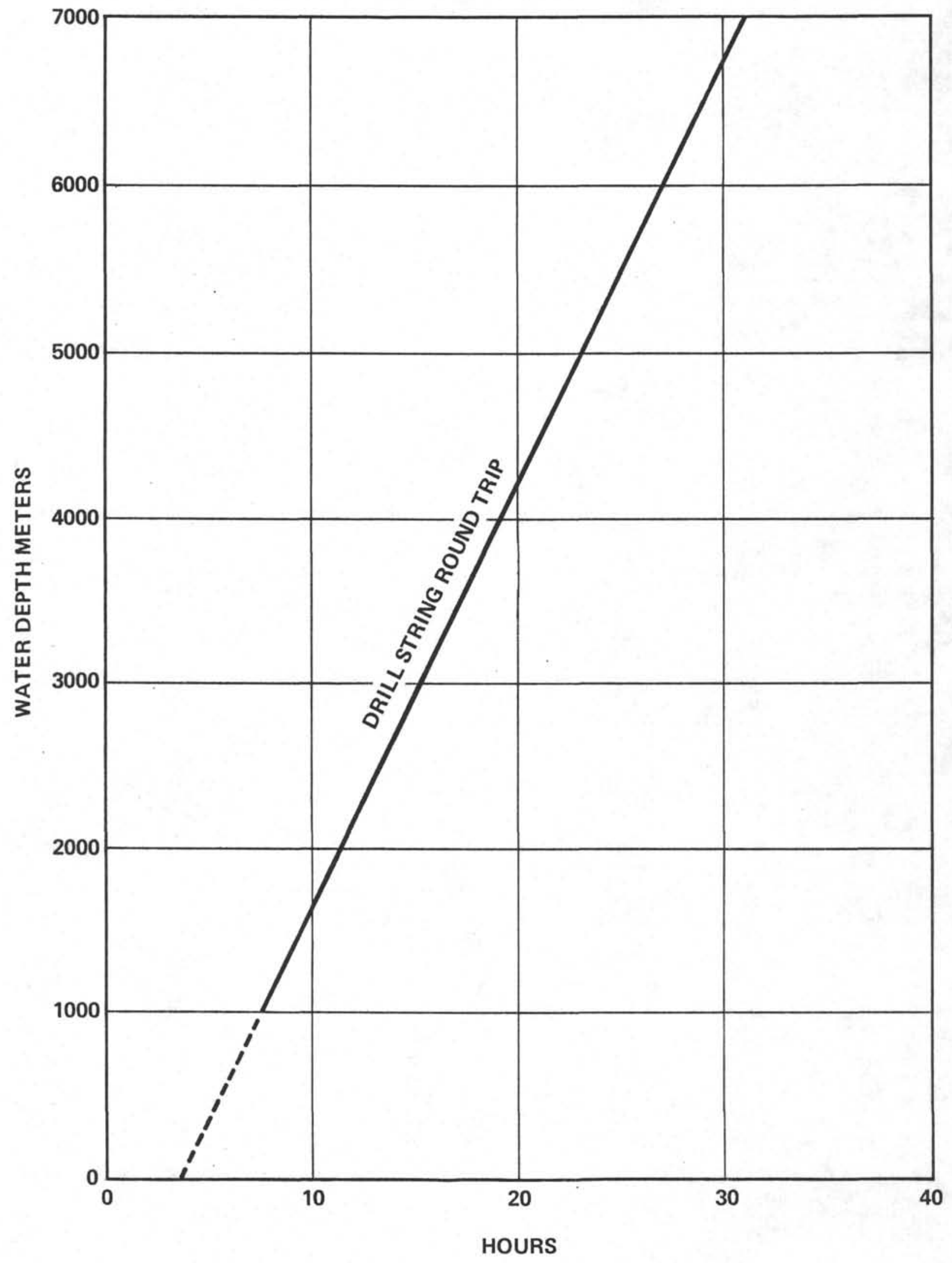


FIG 3

WIRELINE TRIP TIME, CORE BARREL

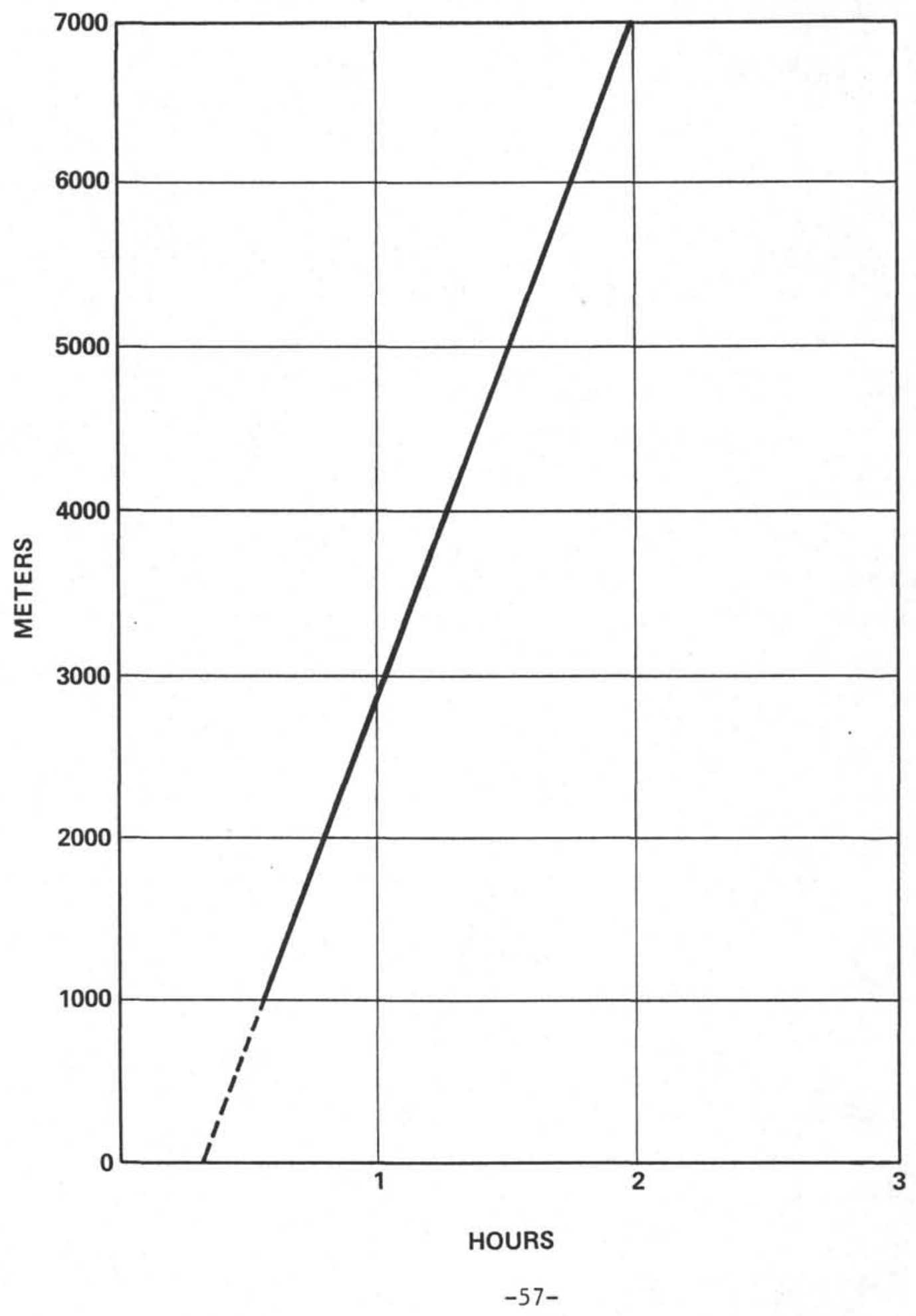


FIG 4

ESTIMATED TIME ON SITE

SINGLE BIT HOLES

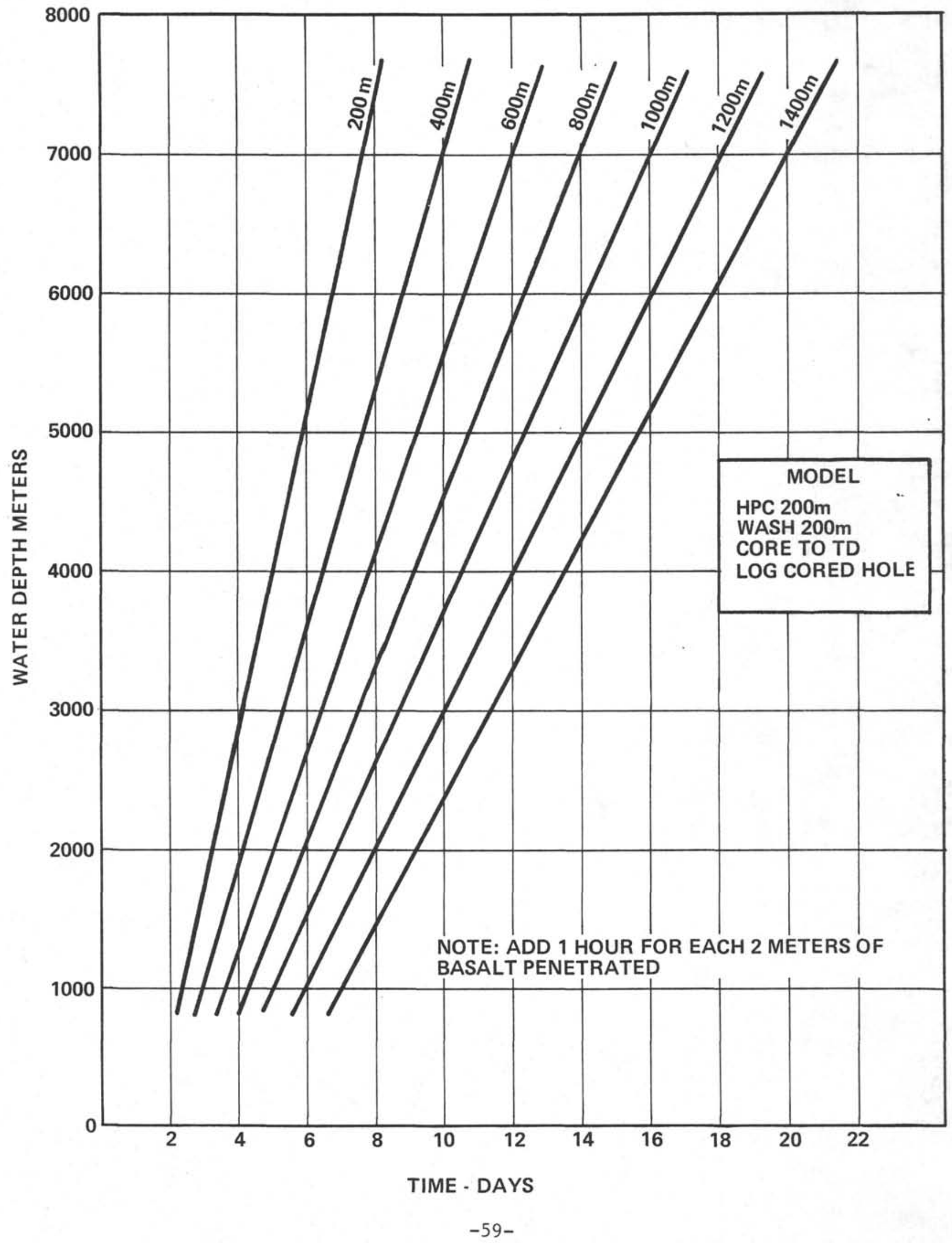


FIG 5

ESTIMATED REENTRY TIME

(RIGGING, WIRELINE ROUND TRIP AND SCANNING)

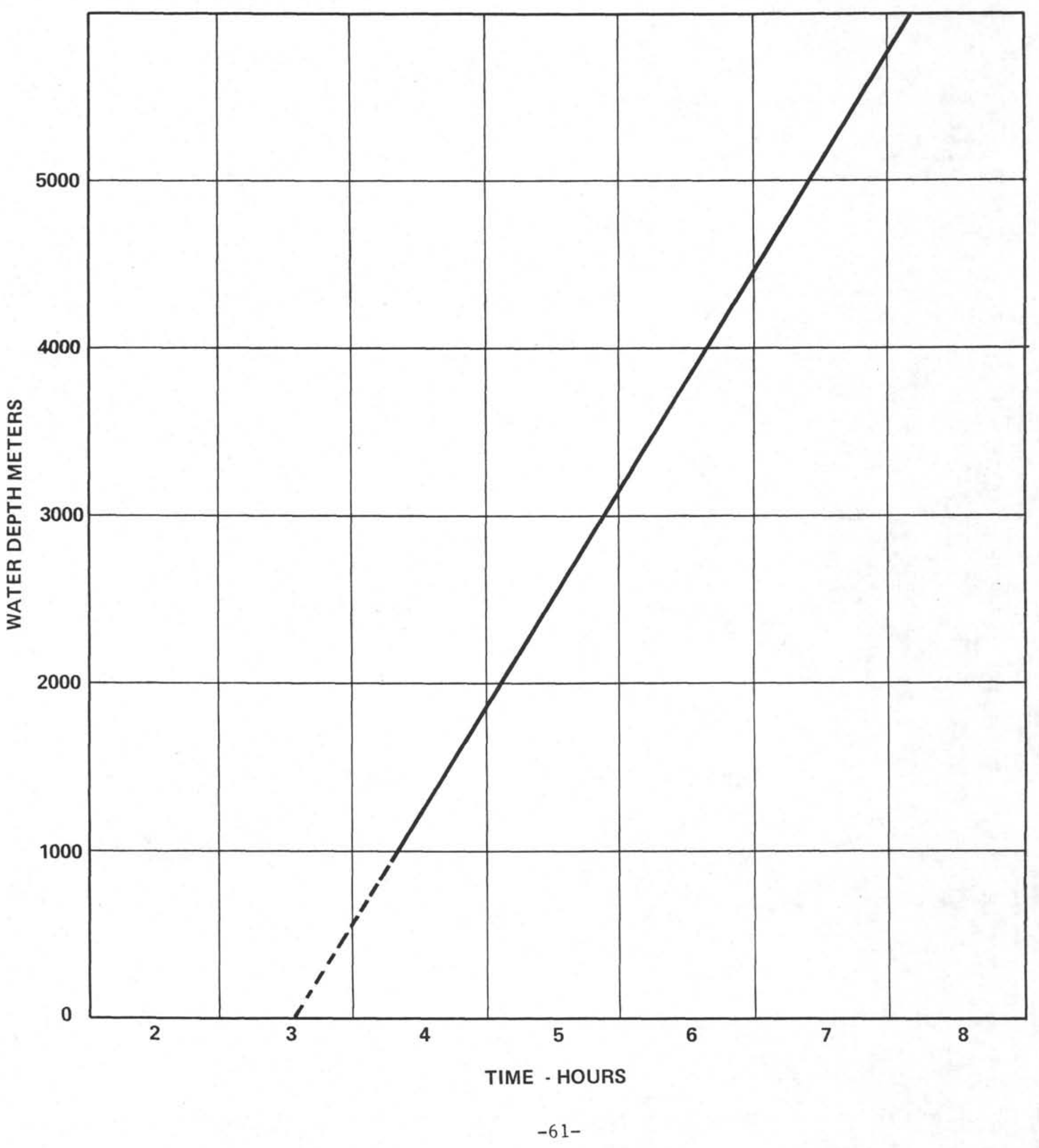


FIG.6

SPEED VS SHAFT RPM

R/V GLOMAR CHALLENGER

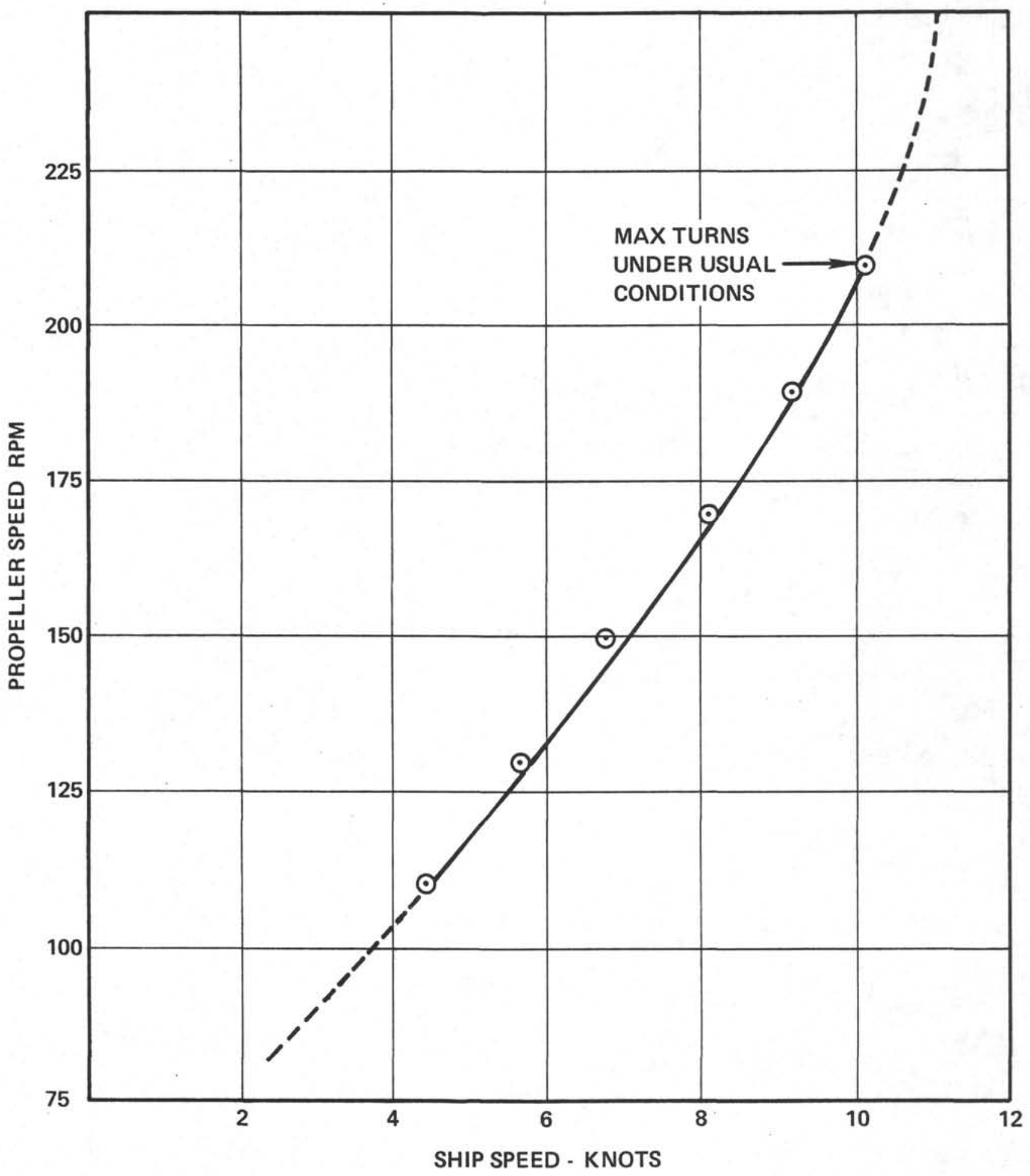


FIG 7

DEEP SEA DRILLING PROJECT

WIRELINE CORING SYSTEM

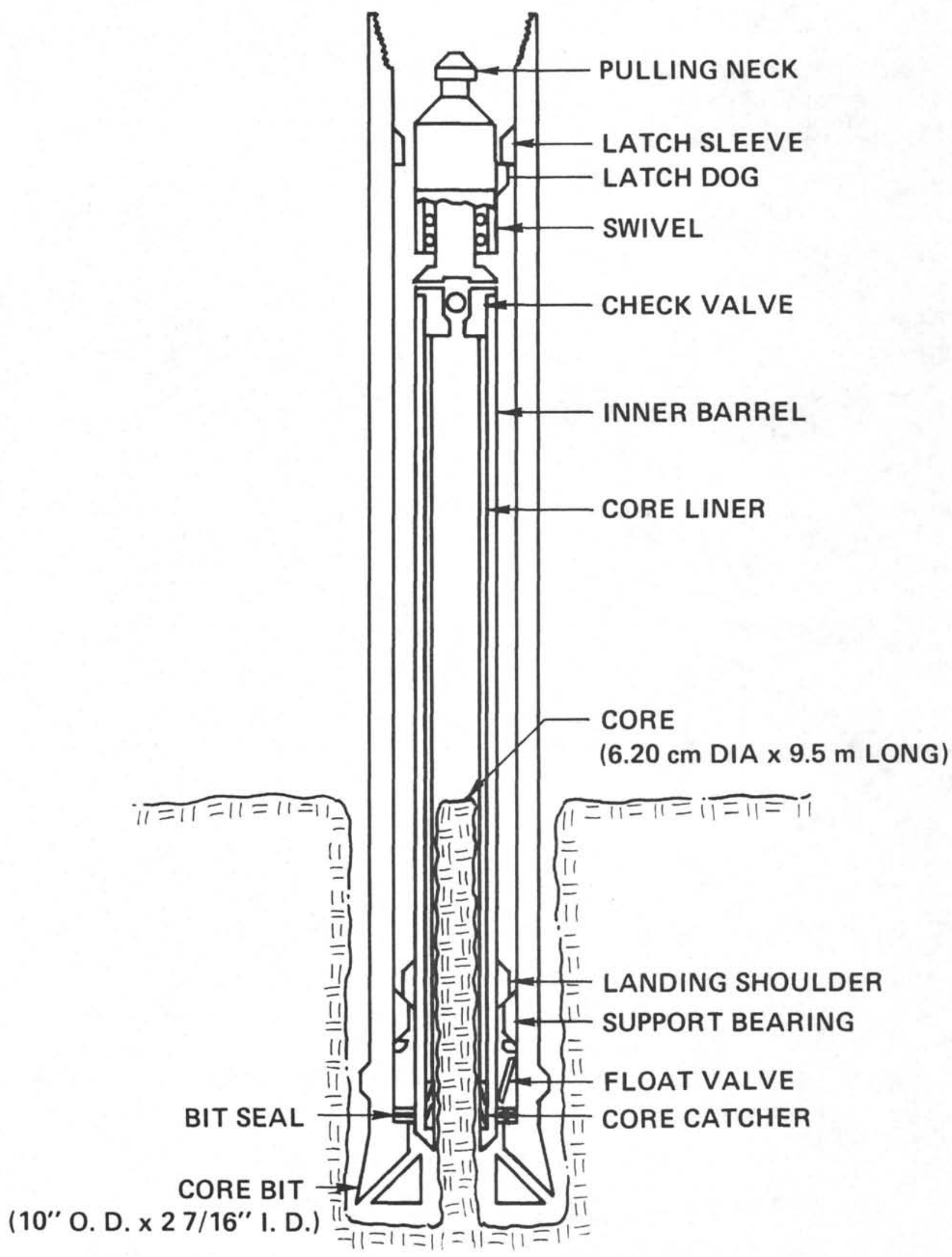


FIG 8

DEEP SEA DRILLING PROJECT

ADVANCED PISTON CORER

(APC)
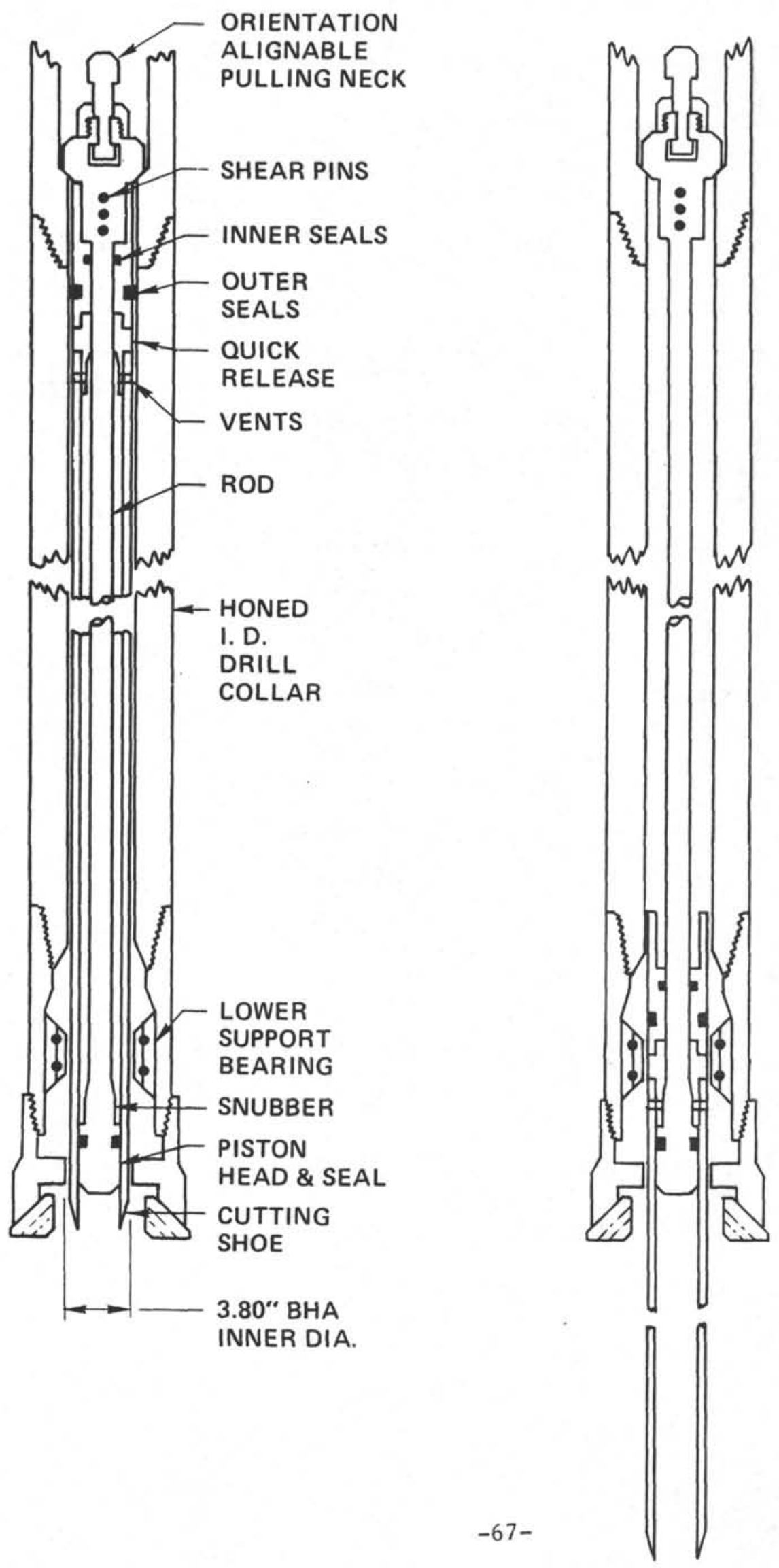
FIG 9

\section{DEEP SEA DRILLING PROJECT}

BOTTOM HOLE ASSEMBLY COMPATIBILITY

ADVANCED PISTON CORER/EXTENDED CORE BARREL

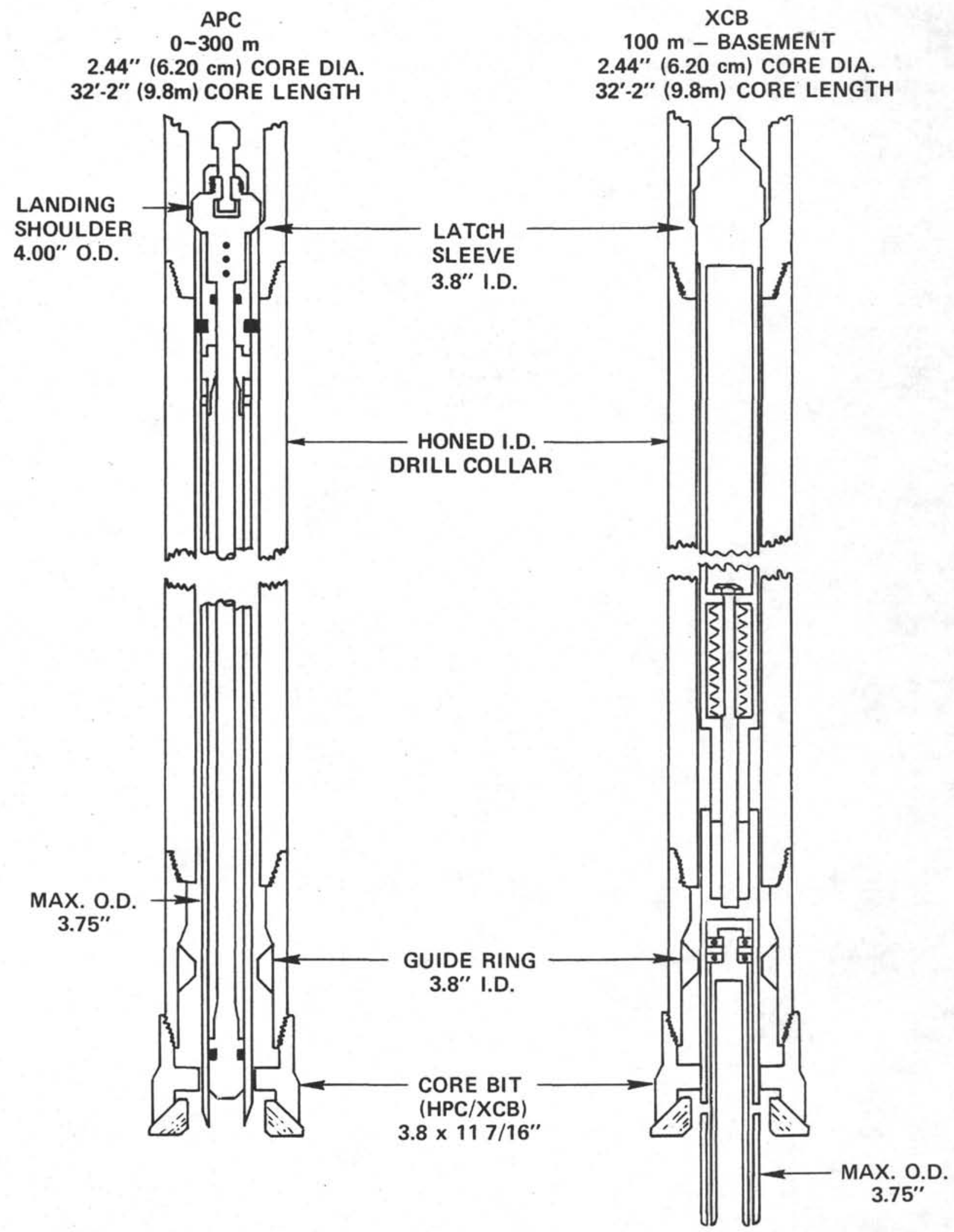


FIG 10

DEEP SEA DRILLING PROJECT

EXTENDED CORE BARREL

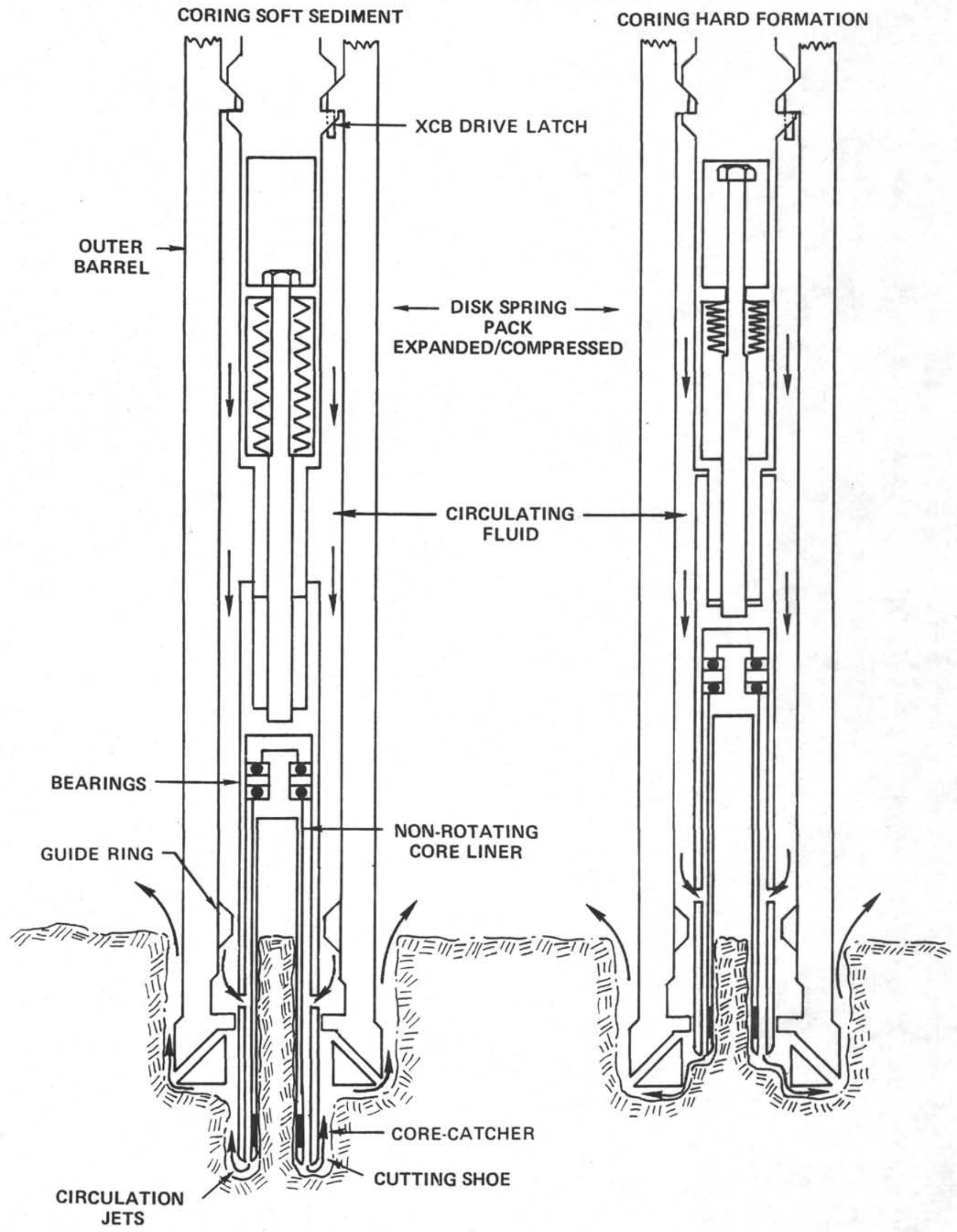


FIG 11

DEEP SEA DRILLING PROJECT

\section{PRESSURE CORE BARREL}

STAGE 1

1. BALL OPEN

2. ASSEMBLY LATCHED

3. CORING AHEAD

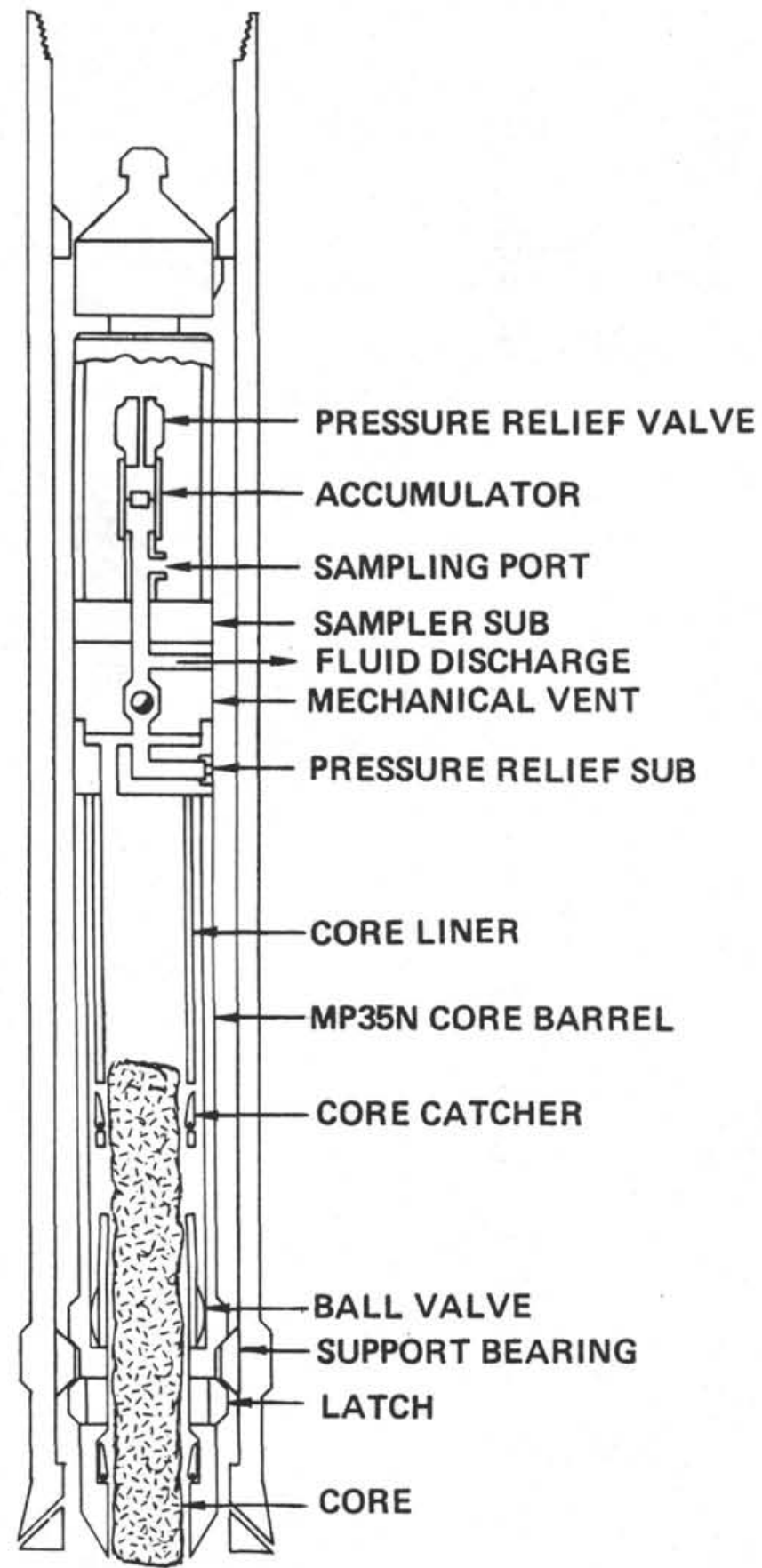

STAGE 2

1. BALL CLOSED

2. ASSEMBLY UNLATCHED

3. RETRIEVING PRESSURIZED CORE

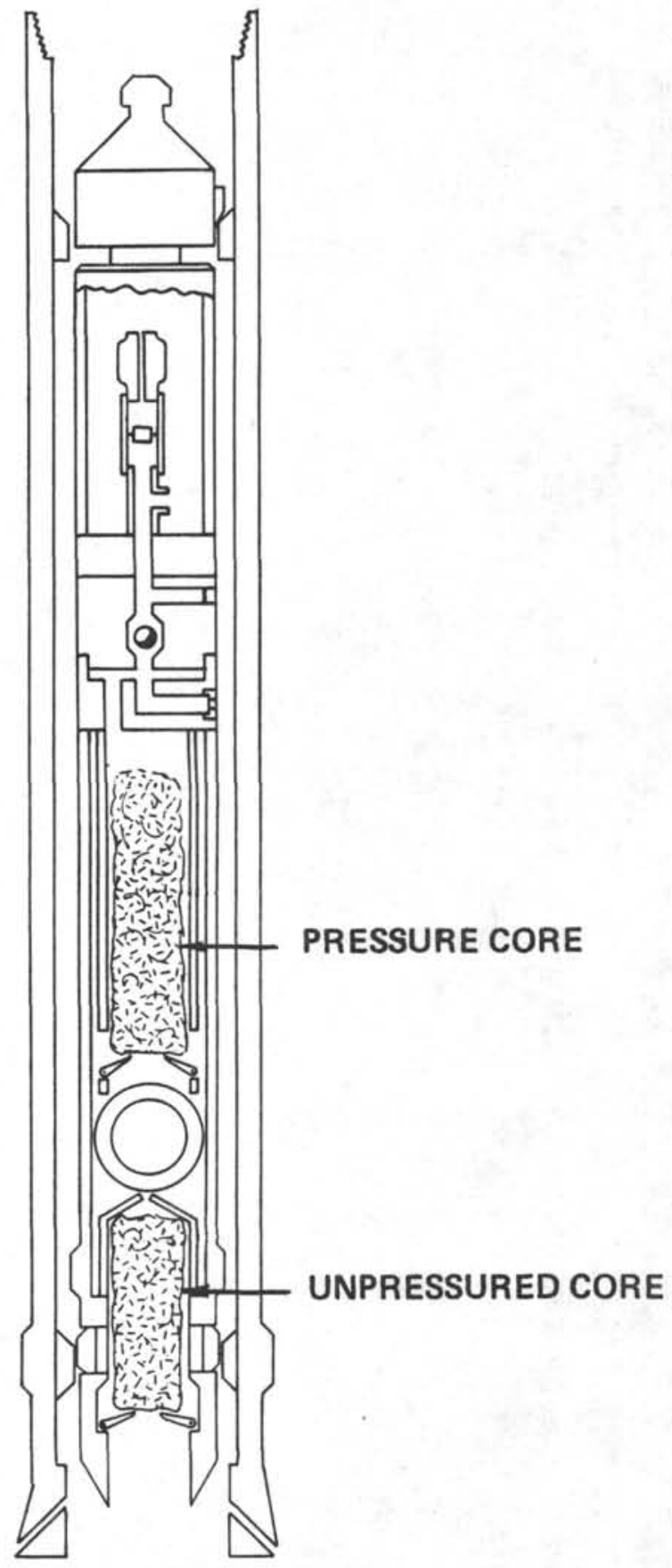


Longest GMI Leg

Longest Science Staff Leg

Shortest Leg

Longest Distance Traveled

Shortest Distance Traveled

Greatest Average Speed

Highest Percentage of Site Time

Most Site Time On One Leg

Most Time On One Site

Most Time On One Hole

Most Sites Investigated

Most Holes Drilled

Most Holes On One Site

Shallowest Water Operations Attempted

Shallowest Water Operations Successful

Deepest Water Operations

Longest Drill String

Deepest Penetration, Multiple Bit

Deepest Penetration, Single Bit

Greatest Total Penetration, One Leg

Deepest Penetration Reaching Igneous Basement

Deepest Multiple Bit Igneous Rock Penetration

Deepest Single Bit Igneous Rock Penetration

Deepest Piston Cored Penetration

Most Cores Attempted, One Leg

Most Cores Attempted, One Site

Most Cores Attempted, One Hole

Greatest Cored Interval, One Leg

Greatest Cored Interval, One Site

Greatest Cored Interval, One Hole

Most Recovered, One Leg

Most Core Recovered, One Site

71.7 days
83.3 days
34.1 days
$9895.0 \mathrm{n} . \mathrm{m}$.
$813.7 \mathrm{n.m}$.
$10.7 \mathrm{kt}$
$80.0 \%$
51.8 days
83.0 days
$73.0 \mathrm{days}$
17
36
10
$197.0 \mathrm{~m}$
$505.0 \mathrm{~m}$
$7044.0 \mathrm{~m}$
$7059.5 \mathrm{~m}$
$1740.0 \mathrm{~m}$
$1545.7 \mathrm{~m}$
$9969.0 \mathrm{~m}$
$1666.5 \mathrm{~m}$
$1076.0 \mathrm{~m}$
$623.0 \mathrm{~m}$
$315.6 \mathrm{~m}$
494
202
141
4579.6
$2074.0 \mathrm{~m}$
$1350.0 \mathrm{~m}$
$3708.9 \mathrm{~m}$
$1055.1 \mathrm{~m}$

71.7 days

SITE

HOLE

39

56

39

93

3

57

61

$69 / 70 / 83$

$69 / 70 / 83$

$6 / 38$ tie

6

70

18

28

60

60

47
95

19

76

$69 / 70 / 83$

59

90

90

$69 / 70 / 83$

$69,70,83$

90

$69 / 70 / 83$

$69 / 70 / 83$

90

93/95
504

504

$504,504 \mathrm{~A}, \mathrm{~B}$

$504 B$

$506 / 507$

176

273

461

461

398

603

534

504

488

599

504

504

504

504

603
$461 \mathrm{~A}$

461, 461A

$398 \mathrm{D}$

$603 \mathrm{~F}$

$534 \mathrm{~A}$

$504 \mathrm{~B}$

$488 \mathrm{~A}$

599A

$504,504 A, B, C$ $504 \mathrm{~B}$

$504,504 \mathrm{~A}, \mathrm{~B}, \mathrm{C}$ $504 \mathrm{~B}$ 
DSDP OPERATIONAL RECORDS

(Continued)

\author{
Most Core Recovered, One Hole \\ Highest Percentage Core Recovered \\ Longest Rotating Bit Life \\ Most Bits Used, One Leg \\ Most Holes Logged, One Leg \\ Most Logs Run, One Leg \\ Longest Continuous Open-Hole Log Interva1 \\ First Successful Logging \\ First Re-entry \\ First Operational Re-entry \\ Most Re-entries, One Leg \\ Most Re-entries, One Hole \\ Deepest Water Re-entry \\ Fastest Re-entry Scan Time \\ Most Records Held By One Leg

$936.6 \mathrm{~m}$

$92.0 \%$

Greatest Penetration By One Bit (Multiple Holes) $2237.0 \mathrm{~m}$

155.8 hrs

15

7

28

$1073.9 \mathrm{~m}$

$\frac{\text { LEG }}{47}$
3
19
70
6
96
64
83
4
$11 \mathrm{C}$
15
83
$69 / 70 / 83 / 92$
91
83

\title{
$\underline{\text { SITE }}$
}

HOLE

398

398D

$186 / 189$

504

504

595

504
504B

504B

$504 \mathrm{~B}$

595B

$504 \mathrm{~B}$ 